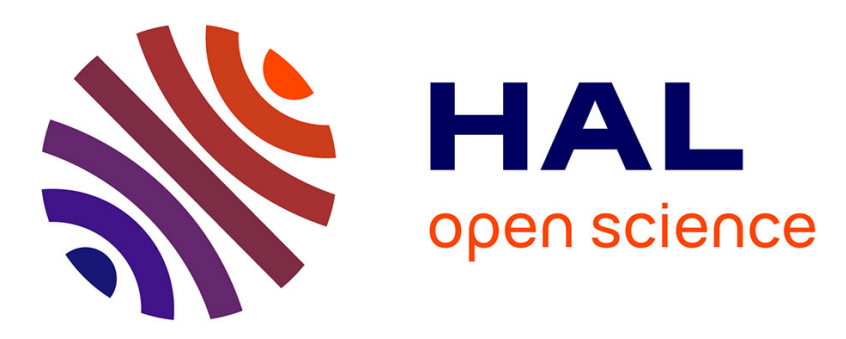

\title{
Fatigue of swollen elastomers
}

Mei Sze Loo, Jean-Benoit Le Cam, Andri Andriyana, Eric Robin, Amalina

\author{
Muhammad Afifi
}

\section{To cite this version:}

Mei Sze Loo, Jean-Benoit Le Cam, Andri Andriyana, Eric Robin, Amalina Muhammad Afifi. Fatigue of swollen elastomers. International Journal of Fatigue, 2015, 74, pp.132-141. 10.1016/j.ijfatigue.2014.11.015 . hal-01148178

\section{HAL Id: hal-01148178 \\ https://hal.science/hal-01148178}

Submitted on 22 Oct 2015

HAL is a multi-disciplinary open access archive for the deposit and dissemination of scientific research documents, whether they are published or not. The documents may come from teaching and research institutions in France or abroad, or from public or private research centers.
L'archive ouverte pluridisciplinaire HAL, est destinée au dépôt et à la diffusion de documents scientifiques de niveau recherche, publiés ou non, émanant des établissements d'enseignement et de recherche français ou étrangers, des laboratoires publics ou privés. 


\title{
Fatigue of swollen elastomers
}

Mei Sze Loo ${ }^{\mathrm{a}}$, Jean-Benoît Le Cam ${ }^{\mathrm{b}}$, Andri Andriyana, ${ }^{\mathrm{a}, *}$ Eric Robin ${ }^{\mathrm{b}}$, Amalina Muhammad Afifi ${ }^{a}$

${ }^{a}$ Department of Mechanical Enginnering, Faculty of Engineering, University of Malaya, 50603 Kuala Lumpur - Malaysia

${ }^{b}$ Université de Rennes 1, Institut de Physique de Rennes UMR CNRS 6251, Campus de Beaulieu, Bât. 10B, 35042 Rennes Cedex-France

\begin{abstract}
The compatibility of the properties of elastomer with conventional diesel fuel has made it favourable in many engineering applications. However, due to global energy insecurity issues, there is an urgent need to find alternative renewable sources of energy as replacements to conventional diesel. In this respect, biodiesel appears to be a promising candidate. Hence, research into the compatibility and fatigue characteristics of elastomers exposed to biodiesel becomes essential. The present paper introduces the first attempt to investigate the effect of different solvents on the fatigue of swollen elastomers. The filled nitrile rubbers are immersed in the palm biodiesel and conventional diesel to obtain the same degree of swelling prior to the application of uniaxial fatigue loading. Field Emission Scanning Electron Microscopy (FESEM) analysis is carried out to observe the fracture surfaces. Stretch-N curves are plotted to illustrate the fatigue life duration. These curves showed that the fatigue lifetime of rubber is the longest for dry rubber and the least for rubber swollen in biodiesel. FESEM micrographs reveal that the loading conditions have no effect on the crack initiation and propagation patterns regardless of the swelling state.
\end{abstract}

Keywords:

Nitrile rubber; swollen rubber; fatigue damage; crack nucleation; biodiesel

\footnotetext{
*Corresponding author. Fax: +60 379675317

Email address: andri.andriyana@um.edu.my (Andri Andriyana)
} 


\section{Introduction}

Conventional petroleum-derived fuels are no longer seen as a futuristic source of fuel because of their ever increasing cost and the continuous diminution in supply. This condition has driven researchers to intensively explore the prospects of biodiesel as a renewable energy alternative for future substitution of current depleting energy resources (Haseeb et al., 2011). Beside being eco-friendly, biodiesel's technical advantages have attracted the interest of researcher to comprehensively investigate its properties, potentials and applications. In Southeast Asia, countries like Malaysia and Indonesia are amongst the largest palm biodiesel producers in the world. Indeed, the production in these countries becomes even more favourable in view of the existing tropical climate (Demirbas, 2009; Atabani et al., 2012).

The reported studies also confirm the influence of biodiesel on elastomers seeing that they have been exploited extensively in the sealing and automotive industries. These studies were motivated by the compatibility of elastomers and biodiesel, which remains a major challenge to date (Haseeb et al., 2010). This concern arises especially when elastomeric components start to degrade in terms of mechanical properties even without any simultaneous imposed loading (Trakarnpruk and Porntangjitlikit, 2008; Haseeb et al., 2010; Alves et al., 2013). Undeniably, the degradation takes place with swelling (Andriyana et al., 2012) when biodiesel creates a hostile environment for elastomeric components.

During service, elastomeric components are usually subjected to cyclic loadings for long durations. For instance, vibration isolators, gaskets and seals are a few common components utilized for this condition. Elastomeric components which endure continuous cyclic loadings may experience fatigue failure (Cadwell et al., 1940). Mars and his co-workers utilized the crack nucleation approach in their works (Mars, 2001; Mars and Fatemi, 2003, 2006) to investigate and to predict the appearance of a $1 \mathrm{~mm}$ fatigue crack length at the surface of rubber. It was explained that fatigue crack nucleation life can be interpreted as the growth period of pre-existing micro-cracks (smaller than $0.1 \mathrm{~mm}$ in size) (Mars and Fatemi, 2003).

Later, Le Cam et al. (2008, 2013) affirmed this finding through a detailed description in their research on the mechanism of crack growth from microscopic flaws, which subsequently led to the appearance of macroscopic crack initiation under uniaxial and multiaxial fatigue loading conditions.

So far, investigations carried out into elastomer fatigue mainly focus on 
dry elastomers. The very few reported works on swollen elastomers under fatigue loading are dedicated to the effect of oil diffusion into elastomers. Cho et al. (2000) discussed the variation of fatigue crack growth resistance of elastomer in the swollen state while Jerrams et al. (2008) presented the Wöhler curves at failure obtained from equibiaxial loading conditions. No studies are reported for the fatigue of swollen elastomers by palm biodiesel to date.

The current studies, which deal with the effect of palm biodiesel diffusion on the behavior of rubbers, investigate the change of mass, volume, hardness and tensile strength of rubbers for different immersion durations (Trakarnpruk and Porntangjitlikit, 2008; Haseeb et al., 2010, 2011; Alves et al., 2013). Haseeb et al. (2011) had immersed nitrile rubbers in diesel and biodiesel for 1000 hours at room temperature prior to subjecting the specimens to tensile tests. They reported lower tensile strength values for the swollen biodiesel rubbers compared with the swollen diesel rubbers. Meanwhile, Alves et al. (2013) conducted similar tests for the nitrile rubbers for a 100 hours immersion duration. Their investigations contradict the results of Haseeb et al. (2011). In their research, the measured tensile strength values for the swollen biodiesel appeared to be higher. This contradiction highlights the importance of immersion duration which governs the final swollen state of rubber without disregarding other essential factors such as the compounding ingredients and specimen geometry.

The present paper proposes a first approach to investigating the response of elastomers swollen by palm biodiesel under fatigue loading conditions. For comparison, fatigue characteristics of elastomers swollen by conventional Malaysian diesel fuel are also investigated. For this purpose, the rubber specimens were immersed in these two different solvents in order to obtain swollen rubbers having the same degree of swelling. Moreover, the physical fatigue damage mechanism induced by the presence of biodiesel in the material at the macro and the microscale will also be probed.

\section{Experimental setup}

\subsection{Material and specimen geometry}

The material used here was of a commercial grade of carbon black-filled nitrile rubber. It was filled with $25 \mathrm{wt} \%$ of carbon black and its hardness was 60 shore A. It is denoted as F-NBR in the rest of the paper. Following Ch'ng et al. (2013), the rubber specimens used in the study corresponded 
to a hollow-diabolo having a height, outer diameter, and wall thickness of 55 $\mathrm{mm}, 25 \mathrm{~mm}$, and $6 \mathrm{~mm}$, respectively. The detailed features of the specimen and chemical compositions of the palm biodiesel (B100) used in he study are provided in Figure 1 and Table 1.

The swollen rubber specimens were obtained by immersing initially dry FNBR in conventional diesel (B0) and palm biodiesel (B100) with the assigned immersion durations in Table 2. The percentage of volume change of the swollen rubbers were calculated using the following equation in accordance to the ASTM D471 standard:

$$
\Delta V \%=\frac{\left(M_{3}-M_{4}\right)-\left(M_{1}-M_{2}\right)}{M_{1}-M_{2}} X 100
$$

where $\Delta V$ is the change in volume, $M_{1}$ is the initial mass of specimen in air, $M_{2}$ is the initial mass of specimen in water, $M_{3}$ is the mass of specimen in air after immersion, $M_{4}$ is the mass of specimen in water after immersion.

In the following sections, the swelling in rubber specimens is described in terms of the degree of swelling, $J_{s}$, defined by the ratio between the volume of swollen specimen and that of a dry specimen. In order to achieve a certain degree of swelling of F-NBR, it is worth noting that the required immersion duration will be different when different solvents are used.

No standard is followed regarding the choice of the specimens and immersion durations. The hardness and mass value of swollen rubbers were measured before and after fatigue testing. Later, the percentage of hardness and mass change were calculated using the following equations to investigate the effect of solvent type on the hardness and on the degree of swelling during the specimens undergoing fatigue testing:

$$
\begin{gathered}
\Delta H=\frac{H_{i}-H_{s}}{H_{s}} X 100 \\
\Delta M=\frac{M_{i}-M_{s}}{M_{s}} X 100
\end{gathered}
$$

where $\Delta H$ is the percentage of change in hardness, $H_{i}$ is the hardness value of the swollen rubber after testing, $H_{s}$ is the hardness value of the swollen rubber before testing, $\Delta M$ is the change in mass, $M_{i}$ is the mass in air of the swollen rubber after testing, $M_{s}$ is the mass in air of the swollen rubber before testing. 


\subsection{Loading conditions}

\subsubsection{Uniaxial cyclic test}

The uniaxial cyclic test was performed to investigate the effect of solvents on stress-softening, also referred to as the Mullins effect in the literature (Mullins, 1948), for the quasi-static behaviour of swollen rubbers. This investigation is essential since the Mullins effect significantly affects fatigue life (Mars and Fatemi, 2004). Indeed, under uniaxial fatigue loading conditions, the loss of stiffness in dry elastomers can lead to an increase in fatigue life. It is therefore relevant to characterize the effect of stress-softening on the fatigue life of swollen rubbers. The tests were carried out using an Instron tensile testing machine with a load cell capacity of $10 \mathrm{kN}$. The rubbers were stretched up to a maximum stretch ratio of 4 for 10 cycles at a $0.1 \mathrm{~s}^{-1}$ constant stretch rate. Note that the stretch is defined by the ratio of the stretched length to the initial length of the rubber specimen. In the case of swollen rubbers, the specimen initial length corresponded to the swollen-unstrained length.

\subsubsection{Uniaxial fatigue test}

The fatigue tests were conducted using a $5 \mathrm{kN}$ Shimadzu 4830 testing machine under prescribed sinusoidal displacement. The load cell capacity used was $5 \mathrm{kN}$. Figure 2 portrays an overview of the experimental setup. In the current investigation, $R_{\epsilon}$ was the loading ratio in terms of strain or the nominal strain loading ratio. It is defined as the ratio between the minimum $\left(\epsilon_{\min }\right)$ and the maximum $\left(\epsilon_{\max }\right)$ strain levels applied to the specimen. The loading condition here corresponds to the repeated uniaxial tension, so $R_{\epsilon}$ was equal to zero. The dry and swollen rubbers were subjected to four levels of maximum stretch at room temperature: 1.5, 1.75, 1.9 and 2. The stretch rate of the material lay within the range of $1 \mathrm{~s}^{-1}<\dot{\lambda}<2.5 \mathrm{~s}^{-1}$ such that it would not induce significant thermal effect in the material. The frequency imposed for all loading conditions was $1 \mathrm{~Hz}$ except for the maximum stretch of 1.5, where a frequency of $2 \mathrm{~Hz}$ was applied. For each test, the number of cycles required for the appearance of $1 \mathrm{~mm}$ crack and for specimen complete rupture was recorded. The test was stopped at 2 million cycles if no crack or rupture is observed in the specimen.

\subsection{Field Emission Scanning Electron Microscopy (FESEM)}

Specimen surfaces were observed with a Jeol JSM T100F Field Emission Scanning Electron Microscope (FESEM). The Energy Dispersive Spectrom- 
eter of X-rays (EDS) coupled with the FESEM were utilized to identify the chemical elements present at the surface of the material. In order to investigate the fracture surfaces, the specimens were previously coated with a thin gold layer by vapour deposition.

\section{Results}

In this section, the results obtained from the cyclic and fatigue tests are reported for dry and swollen rubbers.

\subsection{Hardness and Mass Change}

The measured average hardness values for all specimens before and after fatigue testing are tabulated in Table 3 . The values of change of hardness in percentage in the table are calculated using Equation 2. Table 4 shows the values for mass measurements and the change of mass was calculated using Equation 3. The negative sign in the percentage shows that there was a decrease of hardness and mass for swollen rubbers. The decrease in hardness for swollen B100 rubber was slightly higher than swollen B0 while the decrease in mass for both is comparable. The decrease in mass for both was less than $0.5 \%$ which suggests that the rubber remained swollen throughout the tests with no significant amount of liquid lost. From Table 3, it is observed that the exposure of rubber to solvents leads to a decrease in the hardness. Indeed, before the fatigue tests, the hardness values of dry, swollen B0 and swollen B100 rubbers were 59.5, 54.81 and 54.73 respectively. The corresponding observation could be attributed to the chain scission mechanism (Haseeb et al., 2010) and decreased viscosity due to swelling (Chai et al., 2013). After undergoing fatigue loading, further decreases in the hardness were obseryed: $9 \%$ in swollen B0 and $11 \%$ in swollen B100. It is important to note that this significant change was not observed for the dry rubbers. Hence, this implies that the mechanical loading magnifies the effect of swelling instead of depreciating the hardness of rubber. Since mechanical loading does not induce any additional swelling, the chain scission mechanism seems to be the main reason for the declining values of hardness. This explains the decreasing hardness values from 54.81 and 54.73 (before testing) to 49.84 and 48.62 (after testing) for B0 and B100 respectively.

\subsection{Uniaxial cyclic test}

The stretch-stress responses of dry and swollen rubbers under cyclic loading are given in Figure 3a. In general, it is observed that both dry and swollen 
rubbers show similar inelastic responses. These inelastic responses include stress-softening, hysteresis and permanent set. Similar to the classical softening effect in the dry rubbers, no significant difference of softening was observed from the second cycle onwards for the swollen rubbers. However, it appears that swelling decreased the stress-softening, with a greater decline observed in swollen B0 rubber. At the same time, it was also shown that the stress value was the lowest for the swollen B0 rubber. Figure 3b illustrates the stretch-stress response of rubbers for the 10th cycle which corresponds to the stabilized cycle. In this figure, it is observed that the stabilized cycle loop is almost the same for the swollen B0 and B100. This observation leads to the possibility of excluding the softening effect as the cause of the lowest stress value in swollen B0 rubber. From this perspective, it is important to identify the main driving force for the stretch-stress response obtained from uniaxial fatigue loading. The two possible effects to be considered here are the nature of the swollen rubber due to the effect of diffusion of solvents and the effect from the loading ratio.

\subsection{Uniaxial fatigue tests}

It was observed that the stress decreases for both dry and swollen rubbers as the number of cycles increases, at all maximum stretch levels imposed. Hence in this paper, we will only present one representative stretch-stress plot for dry and swollen rubbers. Figures $4 \mathrm{a}-4 \mathrm{~d}$ show examples of the results at a maximum stretch of 2 for the cycle numbers 10, 100, 1000 and 10000. The decrease in stress value can be explained by the change of the rubber's stiffness, which falls over long periods of time at a constant maximum stretch and can be attributed to the long-term viscosity and irreversible breakage of polymer ehains or crosslinks in the elastomer network (Mars, 2001). The negative stress values in the graphs indicate that compression occurred during the tests due to stress relaxation. For each number of cycles quoted, the peak stresses are identified and the evolutions of peak stress versus the number of cycles are depicted in Figure 5d. Here, the solid lines represent the results obtained from the first specimen and the dashed lines represent the second one. A particular zig-zag pattern is observed for the first 10 cycles and this is purely due to the limitation of the machine which is unable to reach the imposed maximum stretch value from the very first cycle. For both dry and swollen rubbers, the stress decreases until it experiences a steep fall which corresponds to the failure of the rubber specimen. Mars (2001) was able to identify the stabilized response of the rubber after 128 cycle, where a 
constant semi-logarithmic rate of stiffness decrease (plateau) was observed from the stress-strain curve under uniaxial fatigue test. This number of cycles was chosen by the author as a baseline to evaluate the load drop in order to determine end of life. As no plateau was observed in our case, such an approach was not applicable.

A mark was drawn onto each curves to illustrate the appearance of a 1 $\mathrm{mm}$ crack at its corresponding number of cycles. It is apparent that the 1 mm crack emerged at a number of cycles close to rupture, regardless of the maximum stretch level. This indicates that the crack propagated rapidly after the initiation of a $1 \mathrm{~mm}$ crack until it reached complete rupture.

\section{4. $\lambda-N$ curve}

As a first approach, maximum stretch was chosen as the predictor for fatigue lifetime. Indeed, the chosen quantity for plotting the Wohler curves has already been widely used (Andriyana et al., 2010; Mars and Fatemi, 2003; Abraham et al., 2005). The maximum stretch was plotted as a function of number of cycles for the appearance of a $1 \mathrm{~mm}$ crack and complete rupture as shown in Figure 6 and Figure 7 respectively. It should be noted that no crack appeared at all for both dry and swollen rubbers at the maximum stretch level of 1.5. Hence, no data was collected for the rubbers in Figure 6 at the maximum stretch of 1.5. In fact, the end of life of the rubber for this condition was set to be at 2 million cycles even though no occurrence of rupture was observed. Both plots also show the best-fit power-law function to predict the lifetime. In Figure 7, the end of life of rubber at maximum stretch of 1.5 was not taken into consideration for the power-law fit. Both of these curves clearly exhibit similar trend in which the lifetime of the FNBR decreased from dry, swollen B0 and was followed by swollen B100. In addition, the swollen rubber behaved similarly to the dry one with respect to the mechanical properties.

\subsection{Post-mortem analysis}

\subsubsection{At the macroscopic scale}

An overall feature of the ruptured specimen due to fatigue is illustrated in Figure 8. A white dashed line was marked on the specimen to illustrate the crack propagation plane. For this case, the crack propagation plane was not perpendicular to the imposed uniaxial loading. This was not expected in such non-crystallisable rubbers (see the reported work of Le Cam et al. (2014)). It seems to indicate that the hollow geometry had an effect on the mechanical 
field at the local scale and especially in the crack tip vicinity. Moreover, crack initiation at the macroscopic scale was observed at the specimen surface. Further investigations have been carried out at the microscopic scale in order to define the precise location of crack initiation.

\subsubsection{At the microscopic scale}

Once the specimens failed, each of the fracture surfaces was observed by FESEM in order to define the crack initiation location, the origin of crack initiation and the specificities of the morphology of the crack propagation zone. Table 5 summarizes the main features observed at different loading conditions for both dry and swollen rubbers: the presence of smooth and rough surfaces, presence of clouded wool, crack initiation location and rubber balling. Rubber balling is one of the fatigue features previously observed in filled natural rubber (Bhowmick et al., 1980) and short glass fibre-rubber composites (Murthy et al. , 1982). This section divides the achieved results into two categories, which are dry and swollen rubbers, to have a detailed description on the different features reported in the table. The following paragraphs describe the results obtained for dry and swollen rubbers.

\section{(a) Dry rubber}

Figure 9 shows an example of the fracture surface of dry rubber at microscale with the crack initiating at the specimen surface (see the zones indicated by the dotted lines). It can be deduced that the loading had no effect on the crack initiation zone since it appeared consistently on the surface of rubber for all observed fracture surfaces. To the best knowledge of the authors, no inyestigations on the fracture surface of nitrile rubber has yet been reported. Hence, our results can not be correlated to other research works on nitrile rubber. Nonetheless, these results can be compared to existing works such as those reported in natural rubber (Le Cam et al., 2013) or in styrenebutadiene rubber (Le Cam et al., 2014) where the crack initiation occurred from defects located in the subsurface. It has been reported in the literature that the different sources of defects such as carbon black agglomerate failure, cavities at their poles and concentration of cavities favours the crack initiation process (Le Cam et al., 2004, 2013). These defects were distinguished in our samples as shown in Figure 9. In fact, no visible particles were identified for the defect which leads to crack initiation. Apparently, the crack initiation zone for our case was located where the stress concentration was at its 
highest, i.e. at the surface when no stress concentration was induced by the microstructure in this zone. A characteristic pattern for the crack propagation zone is shown in Figure 10a and Figure 10b. This pattern will be termed as clouded wool $(\mathrm{CW})$ in the rest of the paper. It is perceived that the presence of clusters of CW were close to the crack initiation zone while the CW is dispersed away from the this zone. A higher magnification to observe the $\mathrm{CW}$ is shown in Figure 11. In this figure, none of the CW part appeared to be bonded onto the fracture surface. Moreover, only the element of carbon was identified to be present, as proven by the result depicted in Figure 13 obtained from the EDS. This could indicate that friction occurred between the generated surfaces during loading and formed CW. Later, this mechanism caused the ejection of $\mathrm{CW}$ from this zone toward the surface, i.e. the zone of crack initiation. Therefore, this explains the presence of CW cluster in Figure 10b where the formation of it at the site could be considered dubious. To conclude on the CW pattern, it is noted that they seem to be induced by the friction between crack tips that do not occur when the crack propagates perpendicularly to the uniaxial loading. Consequently, this observation highlights that the crack propagates under more complex loading condition than purely uniaxial tensile. Further investigation has to be carried out to determine the origin of the friction; change in the microstructure at the crack tip and the specimen geometry. In addition to CW, rubber balling was also observed as shown in Figure 12. This feature has been previously reported in the work of Bhowmick et al. (1980) under fatigue conditions in filled natural rubber. However, the underlying mechanism producing this feature is unclear. These features have sizes ranging from $12 \mu \mathrm{m}$ to $40 \mu \mathrm{m}$ and are located randomly throughout the crack propagation zone. The formation of them could be due to the impact of the simultaneous effect of continuous cyclic loading on the interaction between carbon black and the rubber matrix. It can be observed that the surface of the rubber ball appeared to be smoother than the matrix. This occurrence raises the question of whether friction had taken place due to the loading, which may have rotated the surface in a circular motion and hence, formed a ball shape.

(b) Swollen rubber

No differences between swollen and dry rubbers have been identified at the crack initiation zone. Similar to the dry rubber, the crack initiated at the surface and the defect leading to crack initiation were not distinguishable. 
In other words, the crack initiated at the location with the highest stress concentration regardless of the type of imposed loading and solvent used.

In the crack propagation zone, the appearance of CW was consistent with the dry rubbers as shown in Figure 14. However, smooth surfaces were only observed in swollen rubbers. These smooth surfaces were found to be either lengthy and parallel to the rivers, or distributed on the whole fracture surface as depicted in Figure 15 and Figure 16 respectively. former is observed in swollen B0 rubbers when subjected to the lowest loading condition while the latter is recognized in swollen B100 rubbers at all loading conditions. Meanwhile, river patterns are one of the common observed fatigue fracture features created by the cleavage of the matrix on different levels resulting in branching appearances or small tributaries of a river (Lampman, 2003; Campbell, 2012). The presence of smooth surfaces seems to be generated by crack propagation in the presence of solvents since it was not observed in any of the dry rubbers. The recurring of smooth surfaces in all the swollen B100 rubbers can be attributed to the higher mobility of the solvent B100 in NBR when compared with B0. This in turn may produce a significant lubricant effect which might be favourable to the formation of smooth surfaces during crack propagation. In fact, more research is currently being performed to enhance understanding of the formation of smooth surfaces.

\section{Discussion}

In this research, we investigated the effect of different solvents at the same swelling level instead for the same immersion duration. The results retrieved from the uniaxial cyclic test have shown that the swollen B100 FNBR attained higher stress levels than the swollen B0 at a given value of swelling (see Figure 3). The result differed from the previous work of Haseeb et al. (2011). In the work of Haseeb et al. (2011), the tensile strength of NBR appeared to be lower for the swollen rubber in B100 as compared to the swollen rubber in B0. The F-NBR samples were immersed for 1000 hours (approximately 1.5months) prior to tensile tests. However, a contradiction of the work of Haseeb et al. (2011) was recognized when Alves et al. (2013) conducted similar tests for the swollen F-NBR (immersed for 100 hours). Their results were in agreement with ours where a higher tensile strength was observed in swollen F-NBR.

These differences can be attributed to the time factor where different immersion durations of the different solvents were needed to achieve the 
same swelling level. In our work, it was proved that the B0 solvent needed approximately 9 times longer to achieve the same amount of swelling (see Table 2) than with the B100 solvent. Hence, it is of high importance to compare the swollen rubbers at similar degrees of swelling to conduct an efficient study from a correlative baseline.

Two types of interactions are considered to have taken place when rubbers are exposed to solvents. The first type is the chemical interaction. Upon exposure to solvents, the tendency of swelling depends on the existence of polarity groups in both rubber and solvents (Mathai et al., 2002; Haseeb et al., 2010; Seehra et al., 2012). This interaction explains that the greater swelling rate in B100 than in B0 could be due to the existence of polarity groups in both NBR and the B100 solvent. Richaud et al. (2013) claimed that the chemical processes are oxidative ones and they can occur through polymer oxidation. Polymer oxidation can be initiated when stabilizer additives are extracted during exposure to solvents, especially for B100. Indeed, the immersion of rubbers in solvents risks the extraction of fillers or additives (Richaud et al., 2013; Seehra et al., 2012; Graham et al., 2006; Trakarnpruk and Porntangjitlikit, 2008). The oxidation process eventually induces chain scission and decreases the polymer resistance to failure (Richaud et al., 2013). Haseeb et al. (2010) also described that the diffusion of the biodiesel into the NBR attacks the polymer backbone through macromolecule chain scission. This mechanism justifies our observation of the decreased value of hardness of swollen rubbers before and after testing.

The second type is the physical interaction. The diffusion of solvent molecules into the rubber is dependent on the mobility of solvent molecules.

Seehra et al. (2012) have demonstrated that the larger the molecular size of solvents, the smaller the change of mass of rubber and the slower the diffusion process at a similar immersion duration for different solvents. This standpoint was adopted to roughly estimate the mobility of B0 and B100 in our investigation. The change of mass after the F-NBR samples were swollen in B0 and B100 were $0.39 \%$ and $0.38 \%$ respectively (refer to Table 4). Since the change of mass for both swollen rubbers were relatively similar, it may be assumed that the molecular size for both solvents was relatively similar, and hence, produced a comparable diffusion rate. Yet, we have shown that different immersion durations are needed for different solvents to achieve the same amount of $J_{s}$. This implies that the diffusion rate is governed by the chemical interaction (polarity) instead of the physical conditions. Considering both types of interactions, it seems that the chemical 
interactions was dominant. Therefore, the shorter immersion duration in B100 solvent is justified and also the shorter fatigue lifetime of swollen B100 rubber as shown in Figure 6 and Figure 7 was demonstrated.

Under cyclic loading, it is observed that both dry and swollen rubbers exhibited inelastic responses such as hysteresis and stress-softening due to the Mullins effect. Stress softening was observed to have taken place primarily after the first loading (see Figure 3a). The softening was evident when a lower stress value was needed for the same applied stretch value. Indeed, swelling decreased the stress-softening due to the Mullins effect (Andriyana et al., 2012). Under fatigue loading, the stress value for the dry rubber was always higher than for the swollen rubber. In fact, the stress values for the swollen B100 rubber was higher than the swollen B0 rubber (see Figure 5d) regardless of the maximum stretch values imposed. This trend is observed to be similar to the mechanical response obtained from the cyclic tests. The higher stress values for swollen B100 rubbers resulted in a shorter lifetime as shown in the $\lambda$-N plots in both Figure 6 and Figure 7. The resultant lower end of life of swollen B100 rubbers could be driven by the imposed loading itself or by the simultaneous effect of the loading condition and the existing damage due due to chain scission in the rubber induced by the B100 solvent.

The slope of the power-law function was used to fit the experimental data in the $\lambda$-N curves. The slope for the dry rubber seems to be steeper compared with the swollen rubbers. This result seem to highlight a higher sensitivity of the swollen rubbers to the imposed loading condition. Meanwhile, the $\lambda$-N plots for the complete rupture in Figure 7 was found to share the trend with Figure 6 after the appearance of $1 \mathrm{~mm}$ crack. The propagation of the cracks after reaching $1 \mathrm{~mm}$ seem to be consistent up to rupture for a given swelling level. Further investigations of the effect of the swelling level on the propagation phase are currently under way in our research group.

Finally, observations at the macro and microscopic scales have shown that cracks initiated at the specimen surfaces. As crack initiation at the macroscopic scale is often described as the result of crack propagation at the microscopic scale, typically from a site in the subsurface zone, it can be speculated if the propagation at the microscopic scale exists for the present case. This could indicate that crack initiation predictors based on the growth of an initial defect might not offer the most suitable approach. Hence, this result creates another opportunity for researchers to further investigate determination of an appropriate fatigue life predictor for swollen rubbers. The crack propagated in a plane which was not perpendicular to the loading direction 
and the loading seemed to have no effect on the crack initiation regardless of the swelling state. The only diversity found was the smooth surfaces observed in the swollen rubbers.

\section{Conclusion}

The fatigue of swollen F-NBR rubbers in two different solvents at the same swelling level have been investigated. The $\lambda$-N curves has been plotted for the appearance of $1 \mathrm{~mm}$ crack and to complete rupture. These plots reveal that the fatigue lifetime was shortest for the swollen B100 rubbers, with their higher stress values compared to swollen B0 rubbers. Meanwhile, the FESEM analysis revealed that similar locations of crack initiation and crack propagation patterns were identified on both dry and swollen rubbers at macro and microscale, for different loading conditions. The effect of different solvents in the swollen rubbers is very intriguing and it should be relevant to study the macromolecular effects of the diffusion of solvents in the rubbers to have a further understanding of the response of rubber under fatigue loading.

Acknowledgement The authors greatly appreciate the financial support of the Ministry of Higher Education Malaysia through High Impact Research Grant MOHE-HIR D000008-16001, University of Malaya (UM) and from the Embassy of France in Mâlaysia.

Abraham, F., Alshuth, T., Jerrams, S., 2005. The effect of minimum stress and stress amplitude on the fatigue life of non strain crystallising elastomers. Materials \& design 26 (3), 239-245.

Alves, S., Mello, V., Medeiros, J., 2013. Palm and soybean biodiesel compatibility with fuel system elastomers. Tribol. Int. 65, 74-80.

Andriyana, A., Chai, A., Verron, E., Johan, M., 2012. Interaction between diffusion of palm biodiesel and large strain in rubber: Effect on stresssoftening during cyclic loading. Mech. Res. Commun. 43, 80-86.

Andriyana, A., Saintier, N., Verron, E., 2010. Configurational Mechanics and Critical Plane Approach: Concept and applicationto fatigue failure analysis of rubberlike materials. Int. J. Fatigue 32 (10), 1627-1638. 
Atabani, A., Silitonga, A., Badruddin, I. A., Mahlia, T., Masjuki, H., Mekhilef, S., 2012. A comprehensive review on biodiesel as an alternative energy resource and its characteristics. Renew. Sustain. Energy Rev. 16 (4), 2070-2093.

Bhowmick, A. K., Nando, G. B., Basu, S.,De, S. K. 1980. Scanning electron microscopy studies of fractured natural rubber surfaces. Rubb. Chem. Technol. 53 (2), 327-334.

Cadwell, S. M., Merrill, R. A., Sloman, C. M., Yost, F. L., 1940. Dynamic fatigue life of rubber. Ind. Eng. Chem. 12 (1), 19-23.

Chai, A. B., Andriyana, A., Verron, E., Johan, M. R., 2013. Mechanical characteristics of swollen elastomers under cyclic loading. Mater. Des. 44, $566-572$.

Campbell, F. C.,(2012). Fatigue and fracture: understanding the basics. ASM International.

Ch’ng, S. Y., Andriyana, A., Verron, E., Kahbasi, O., Ahmad, R., 2013. Development of a novel experimental device to investigate swelling of elastomers in biodiesel undergoing multiaxial large deformation. Experimental Mechanics 53 (8), 1323-1332.

Cho, K., Jang, W. J., Lee, D., Chun, H., Chang, Y.-W., 2000. Fatigue crack growth of elastomers in the swollen state. Polymer 41 (1), 179 - 183.

Demirbas, A., 2009. Political, economic and environmental impacts of biofuels: A review. Appl. Energy 86, S108-S117.

Graham, J. L., Striebich, R. C., Myers, K. J., Minus, D. K., Harrison, W. E., Mar. 2006. Swelling of nitrile rubber by selected aromatics blended in a syntheticjet fuel. Energy \& Fuels 20 (2), 759-765.

Haseeb, A. S. M. A., Fazal, M. A., Jahirul, M. I., Masjuki, H. H., 2011. Compatibility of automotive materials in biodiesel: A review. Fuel 90 (3), 922-931.

Haseeb, A. S. M. A., Masjuki, H. H., Siang, C. T., Fazal, M. A., 2010. Compatibility of elastomers in palm biodiesel. Renew. Energ. 35 (10), 23562361. 
Jerrams, S., Hanley, J., Murphy, N., Ali, H., 2008. Equi-biaxial fatigue of elastomers: The effect of oil swelling on fatigue life. Rubber Chem. Technol. 81 (4), 638-649.

Lampman, S., 2003. Characterization and failure analysis of plastics. ASM International.

Le Cam, J.-B., Huneau, B., Verron, E., 2013. Fatigue damage in carbon black filled natural rubber under uni-and multiaxial loading conditions. Int. J. Fatigue 52, 82-94.

Le Cam, J.-B., Huneau, B., Verron, E., 2014. Failure analysis of carbon black filled styrene butadiene rubber under fatigue loading conditions. Plastics, Rubber and Composites 43 (6), 187-191.

Le Cam, J.-B., Huneau, B., Verron, E., Gornet, L., 2004. Mechanism of fatigue crack growth in carbon black filled natural rubber. Macromolecules 37 (13), 5011-5017.

Le Cam, J.-B., Huneau, B., Verron, E., 2008. Description of fatigue damage in carbon black filled natural rubber. Fatigue \& Fracture of Engineering Materials \& Structures 31 (12), 1031-1038.

Mars, W., Fatemi, A., 2004. Factors that affect the fatigue life of rubber: a literature survey. Rubber Chemistry and Technology 77 (3), 391-412.

Mars, W. V., 2001. Multiaxial fatigue of rubber. Ph.D. thesis, University of Toledo.

Mars, W. V., Fatemi, A., 2003. Fatigue crack nucleation and growth in filled natural rubber. Fatigue Fract. Eng. Mater. Struct. 26 (9), 779-789.

Mars, W. V., Fatemi, A., 2006. Nucleation and growth of small fatigue cracks in filled natural rubber under multiaxial loading. Journal of materials science 41 (22), 7324-7332.

Mathai, A. E., Singh, R., Thomas, S., 2002. Transport of substituted benzenes through nitrile rubber/natural rubber blend membranes. Journal of membrane science 202 (1), 35-54.

Mullins, L., 1948. Effect of stretching on the properties of rubber. Rubber Chemistry and Technology 21 (2), 281-300. 
Murthy, V. M., Bhowmick, A. K., De, S. K., 1982. Scanning electron microscopy studies of failure surfaces of short glass fibre-rubber composites. Journal of Materials Science. 17 (3), 709-716.

Richaud, E., Djouani, F., Fayolle, B., Verdi, J., Flaconneche, B., 2013. New insights in polymer-biofuels interaction. Oil \& Gas Science and Technology-Revue dIFP Energies nouvelles.

Seehra, M., Yalamanchi, M., Singh, V., 2012. Structural characteristics and swelling mechanism of two commercial nitrile-butadiene elastomers in various fluids. Polymer Testing 31 (4), 564-571.

Trakarnpruk, W., Porntangjitlikit, S., 2008. Palm oil biodiesel synthesized with potassium loaded calcined hydrotalcite and effect of biodiesel blend on elastomer properties. Renew. Energ. 33 (7), 1558-1563. 


\section{List of Tables}

1 Properties of B100 palm biodiesel . . . . . . . . . . . 20

2 Immersion duration of rubber with their respective solvents. . 20

3 Hardness values of dry and swollen rubbers before and after fatigue tests. . . . . . . . . . . . . . 20 20

4 Mass of dry and swollen rubbers before and after fatigue test. 20

5 Features observed in the rubber. . . . . . . . . . . . 20 


\section{List of Figures}

1 Geometry of rubber specimen. . . . . . . . . . . . . . . . 21

2 Overview of experimental setup. . . . . . . . . . . . 22

3 Stretch-stress response of rubbers under uniaxial cyclic loading. 23

4 The stretch-stress responses at different cycles at maximum stretch of 2 under fatigue loading. . . . . . . . . . . . . 24

5 Evolutions of peak stress as a function of number of cycles for various values of maximum stretch. . . . . . . . . . . 25

$6 \lambda$-N curve for the appearance of $1 \mathrm{~mm}$ crack of NBR. . . . . 26

$7 \lambda$-N curve for the complete rupture of NBR. . . . . . . . . 27

8 Overall feature of the ruptured rubber upon the completion of the fatigue test. . . . . . . . . . . . . . . . . . 28

9 Crack initiation zone of dry rubber. . . . . . . . . . . . . . . . 29

10 Crack propagation pattern of dry rubber. . . . . . . . . . 30

11 Higher magnification of clouded wool. . . . . . . . . . . . . . 31

12 Rubber balling on the fracture surface. . . . . . . . . . . . . 32

13 Composition of elements present in clouded wool. . . . . . . . 33

14 Presence of CW along the river. . . . . . . . . . . . . . 34

15 Lengthy smooth surfaces parallel to the river. . . . . . . . . 35

16 Distributed smooth surfaces on the whole fracture surface. . . 37 

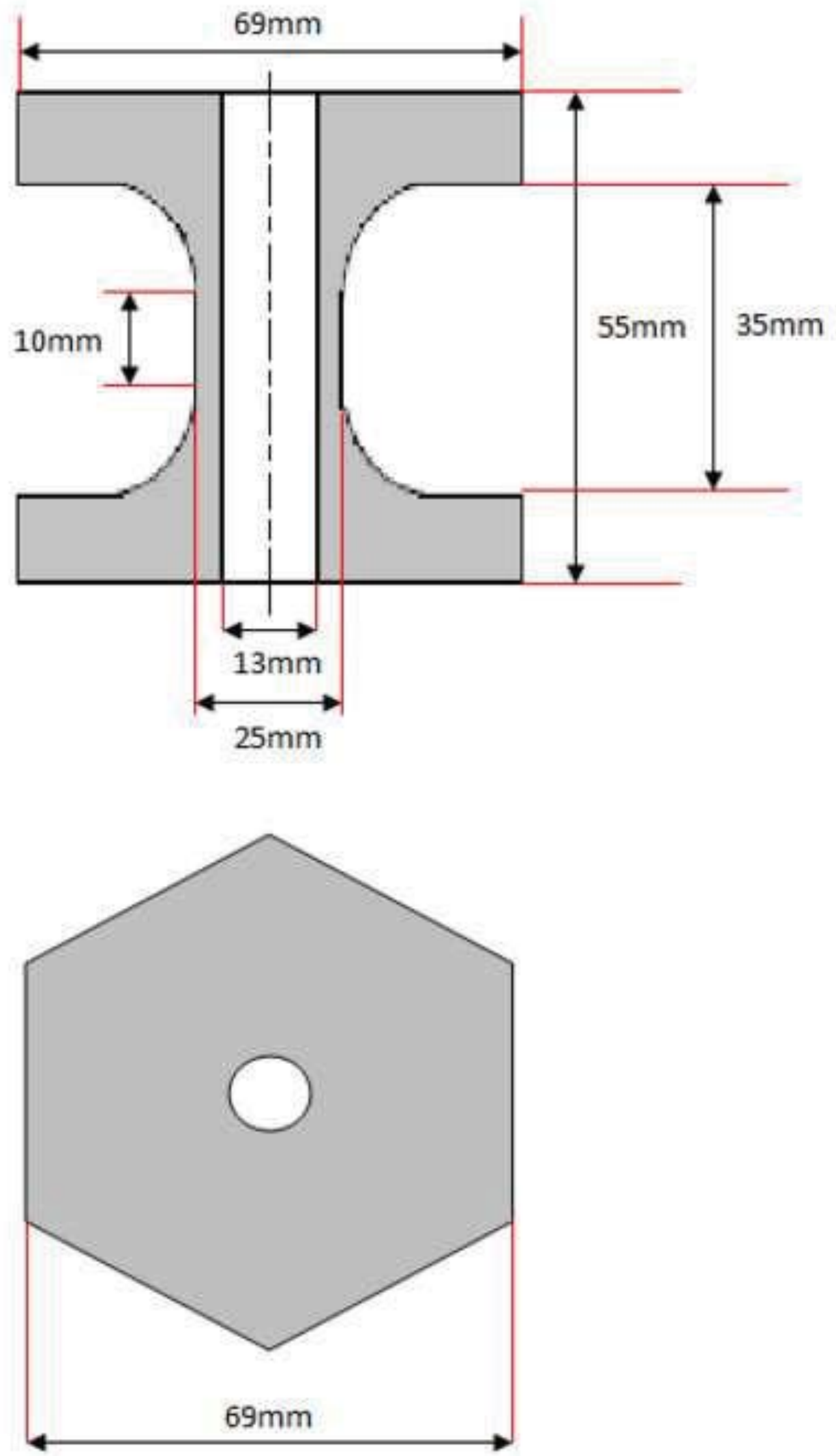


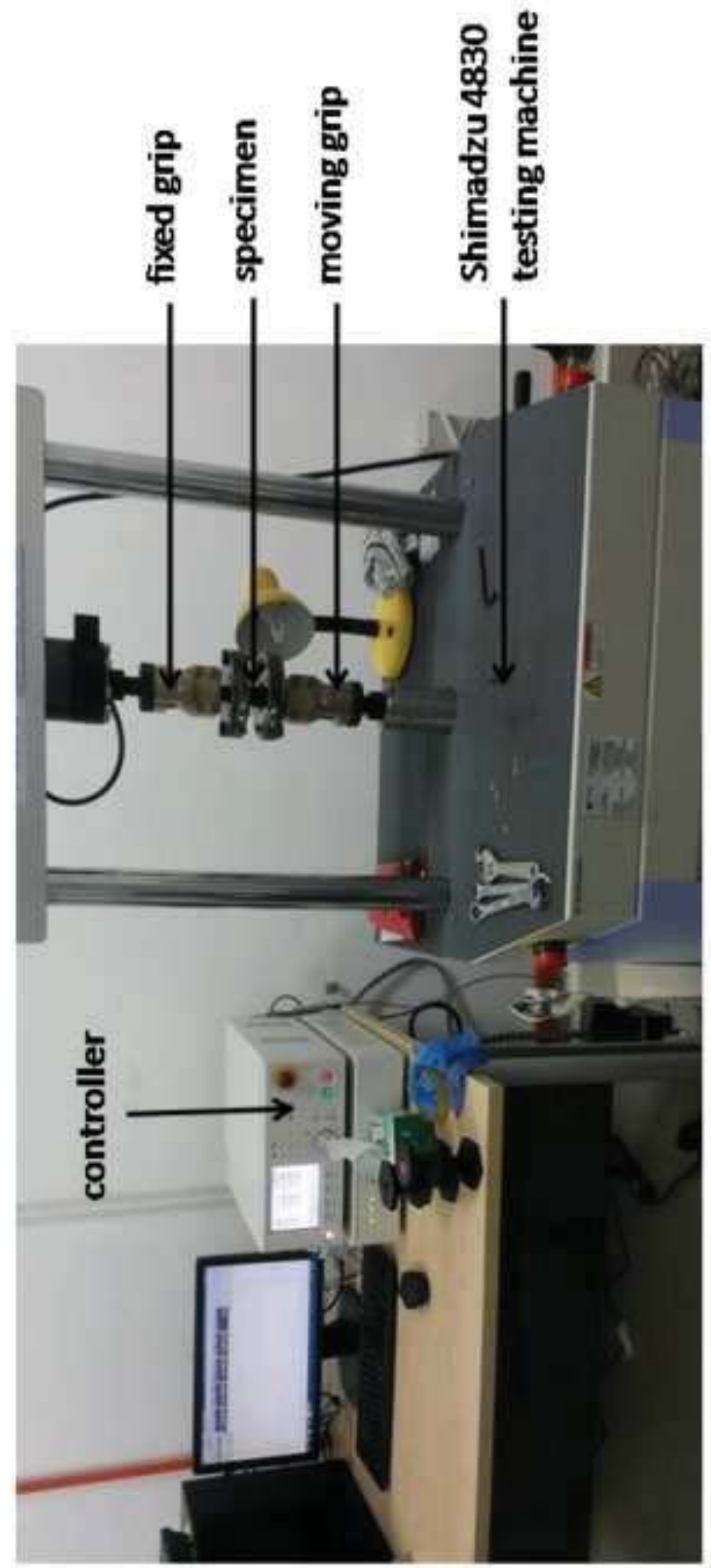

N

온 


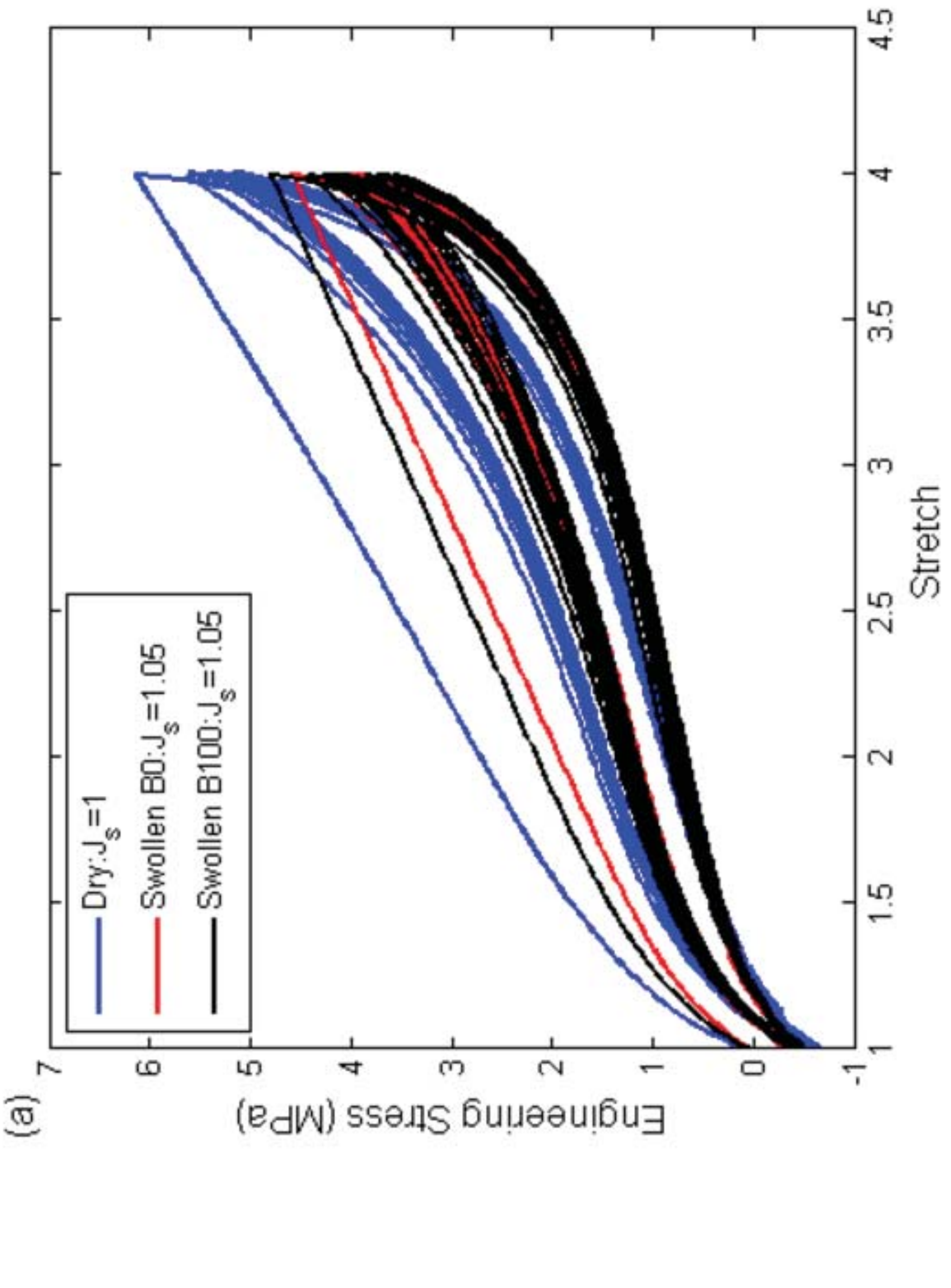




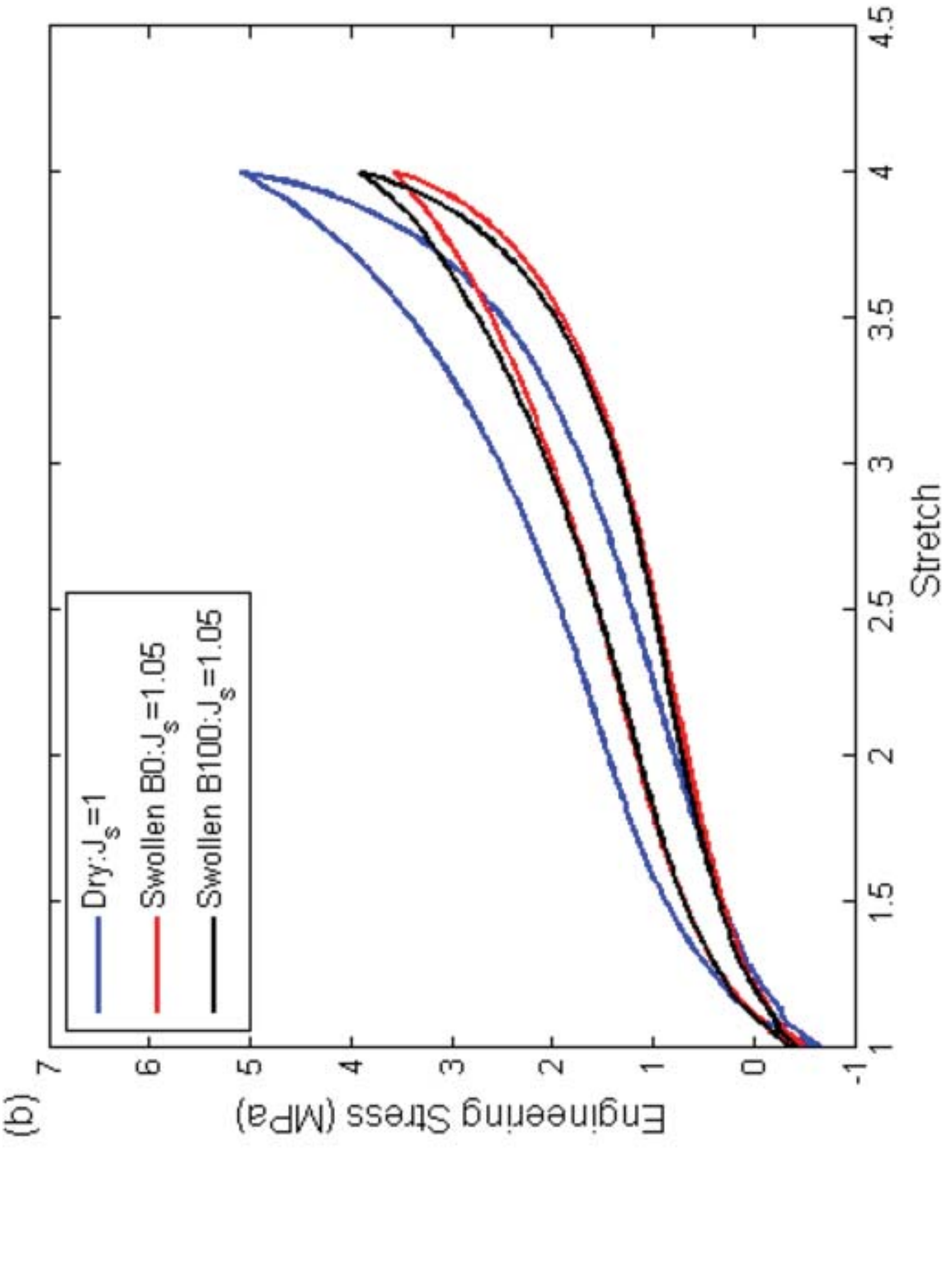




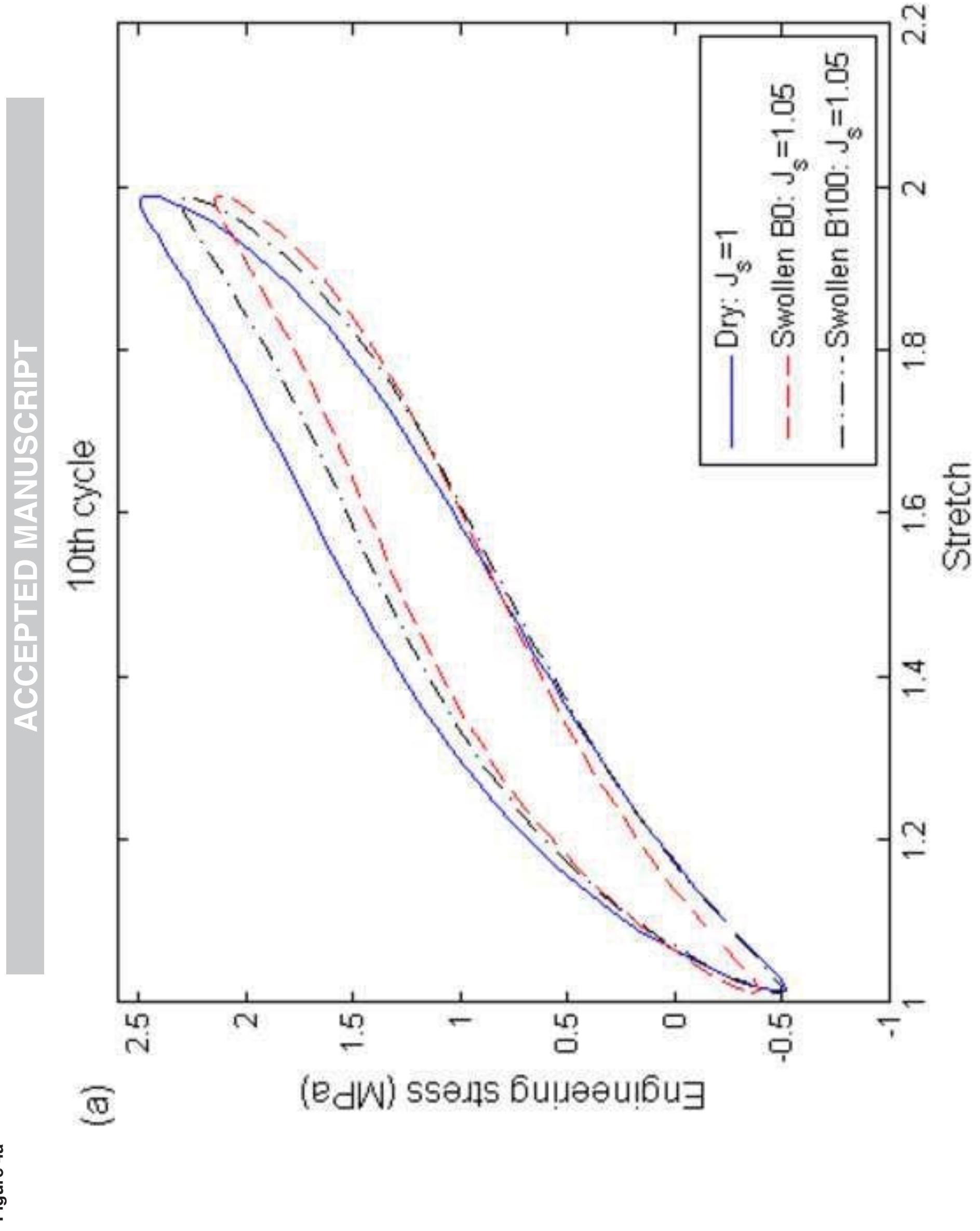




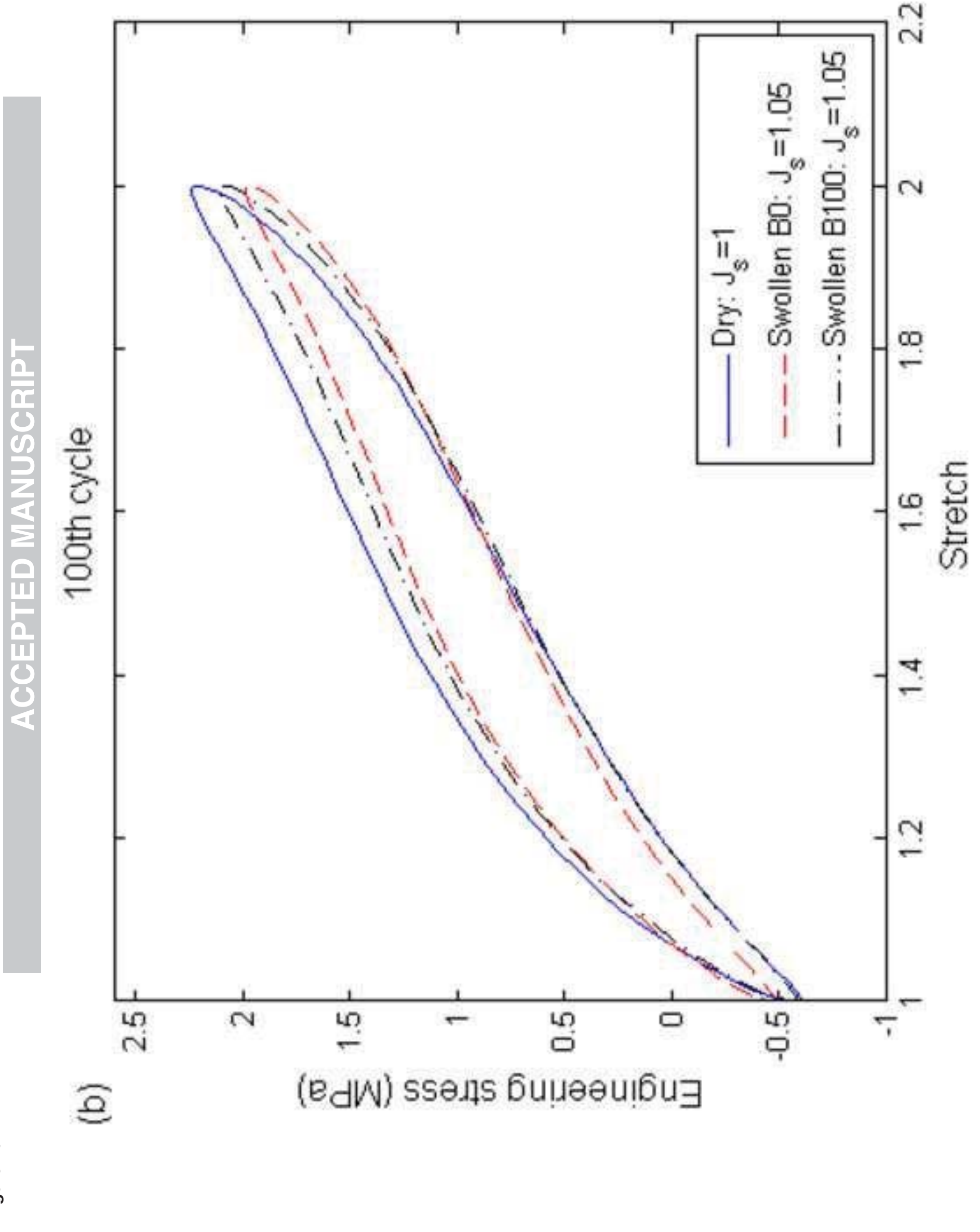




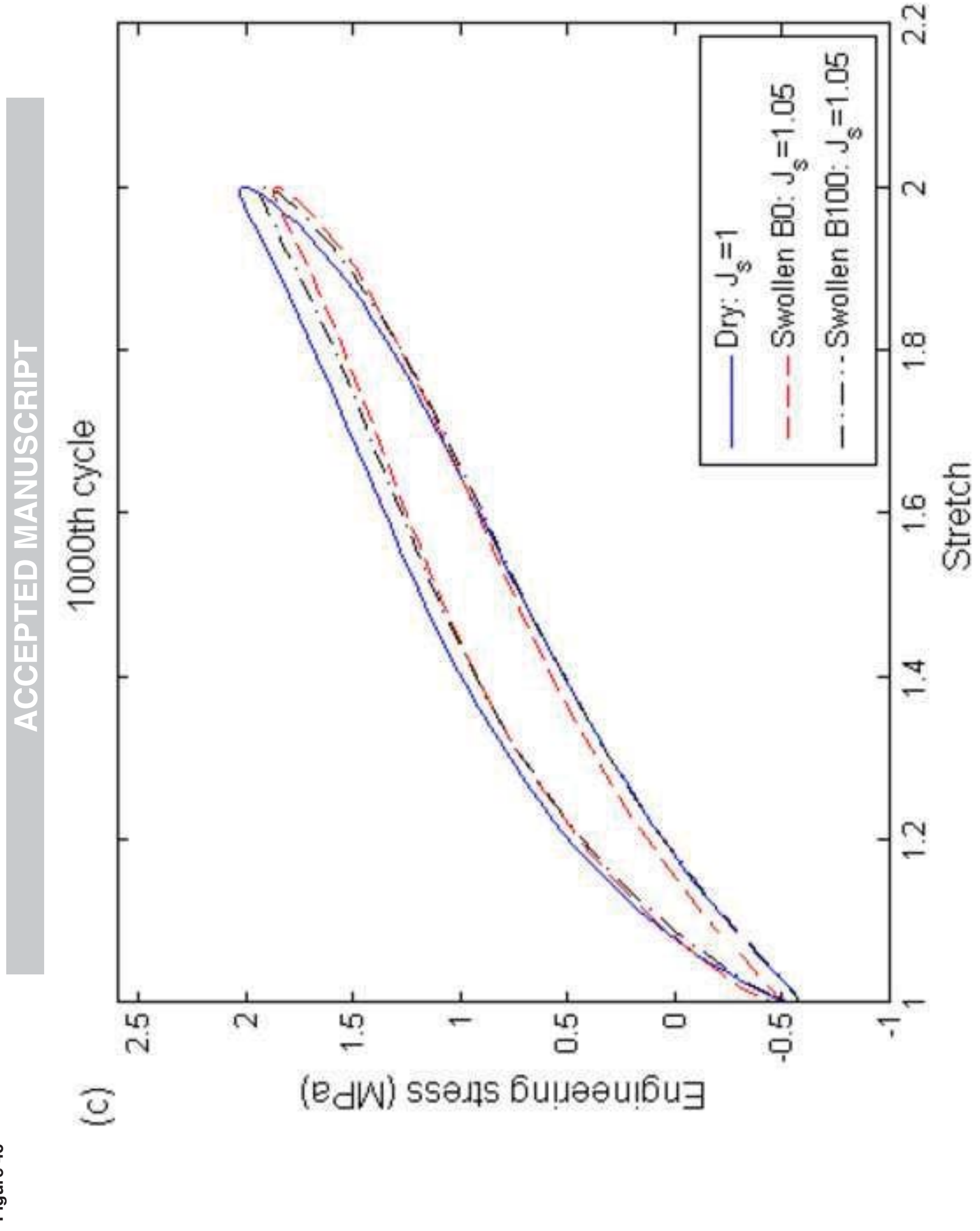




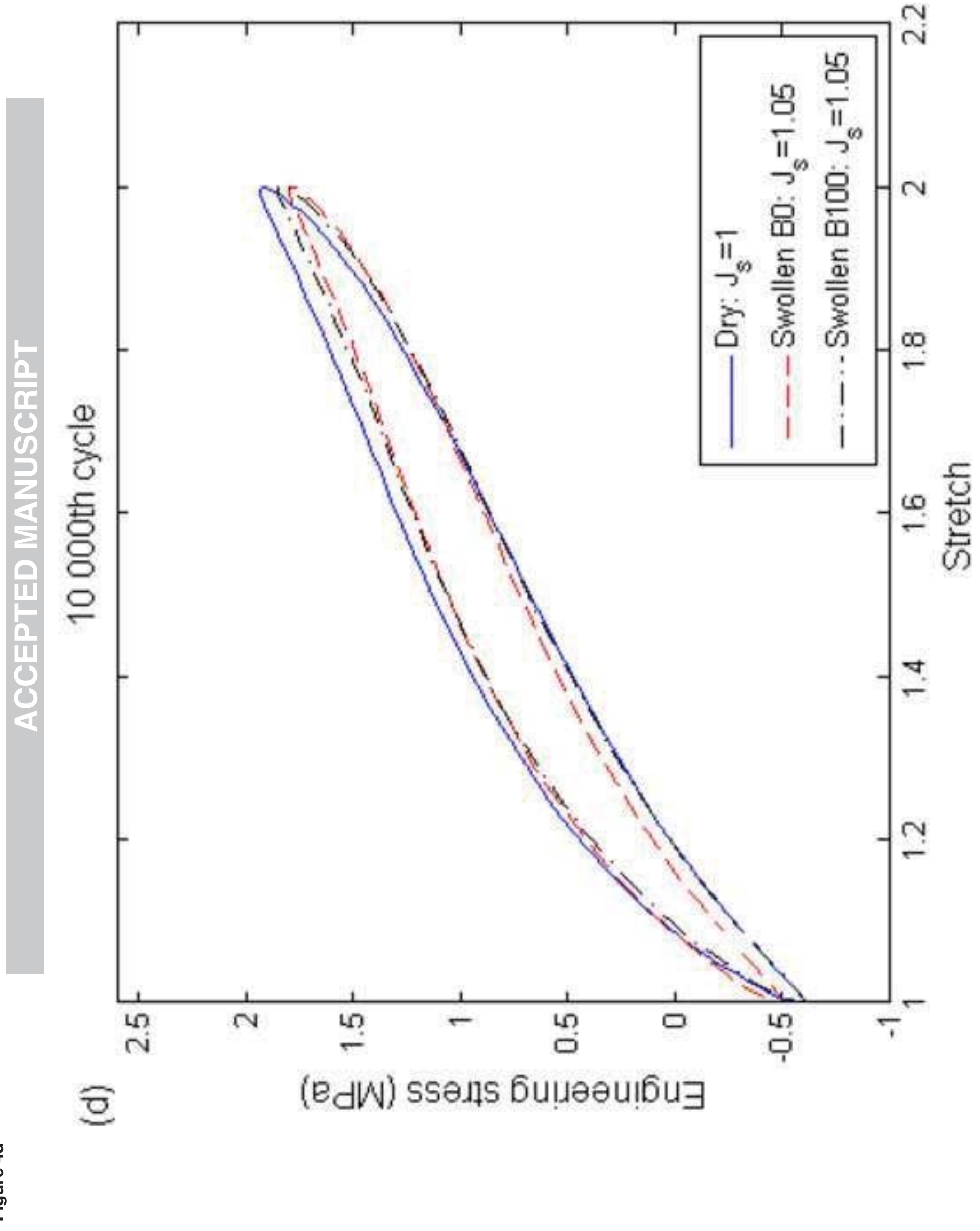




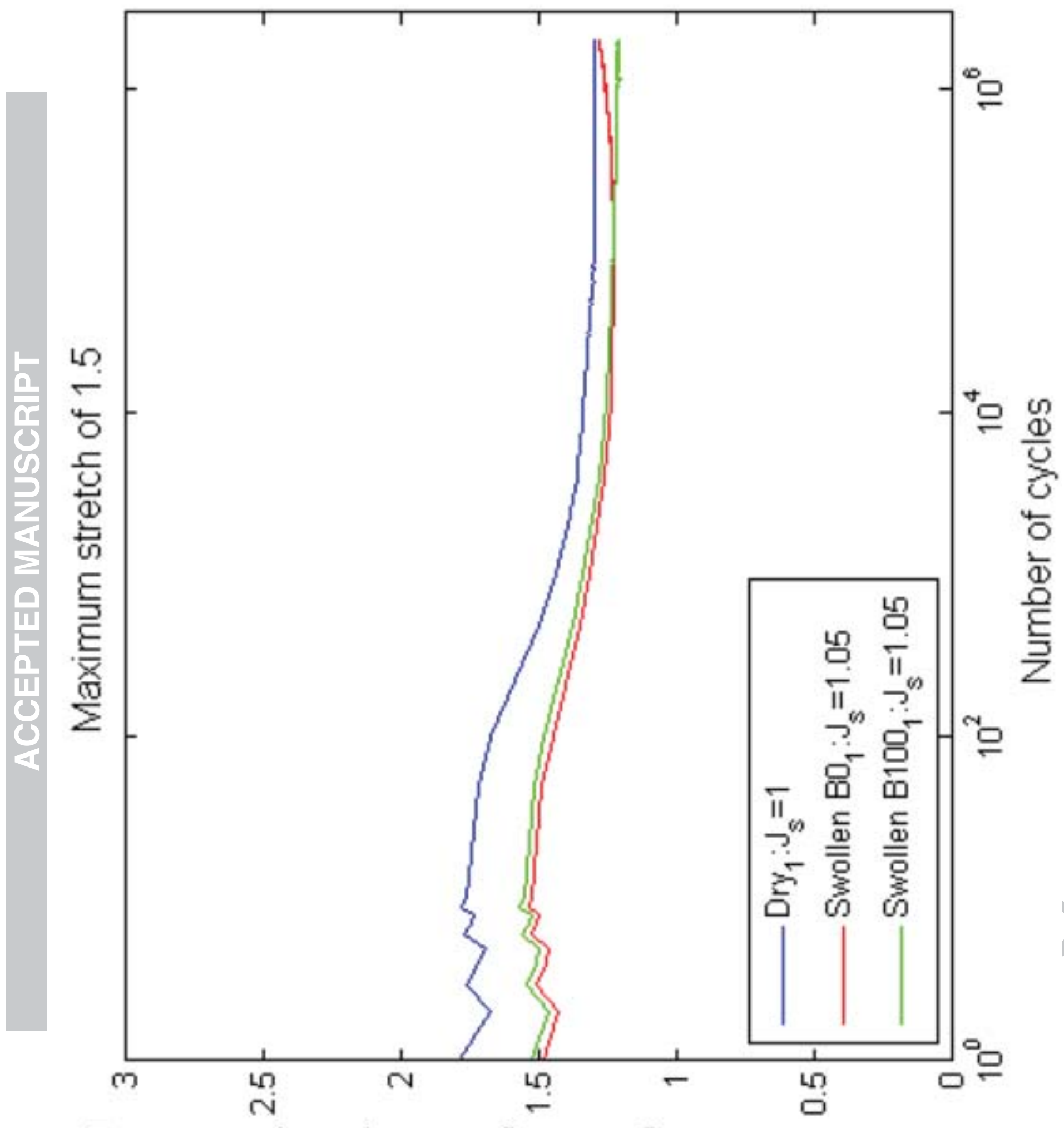

(ె)

(edW) ssəגı бu!̣әəu!̣uә yeəd 


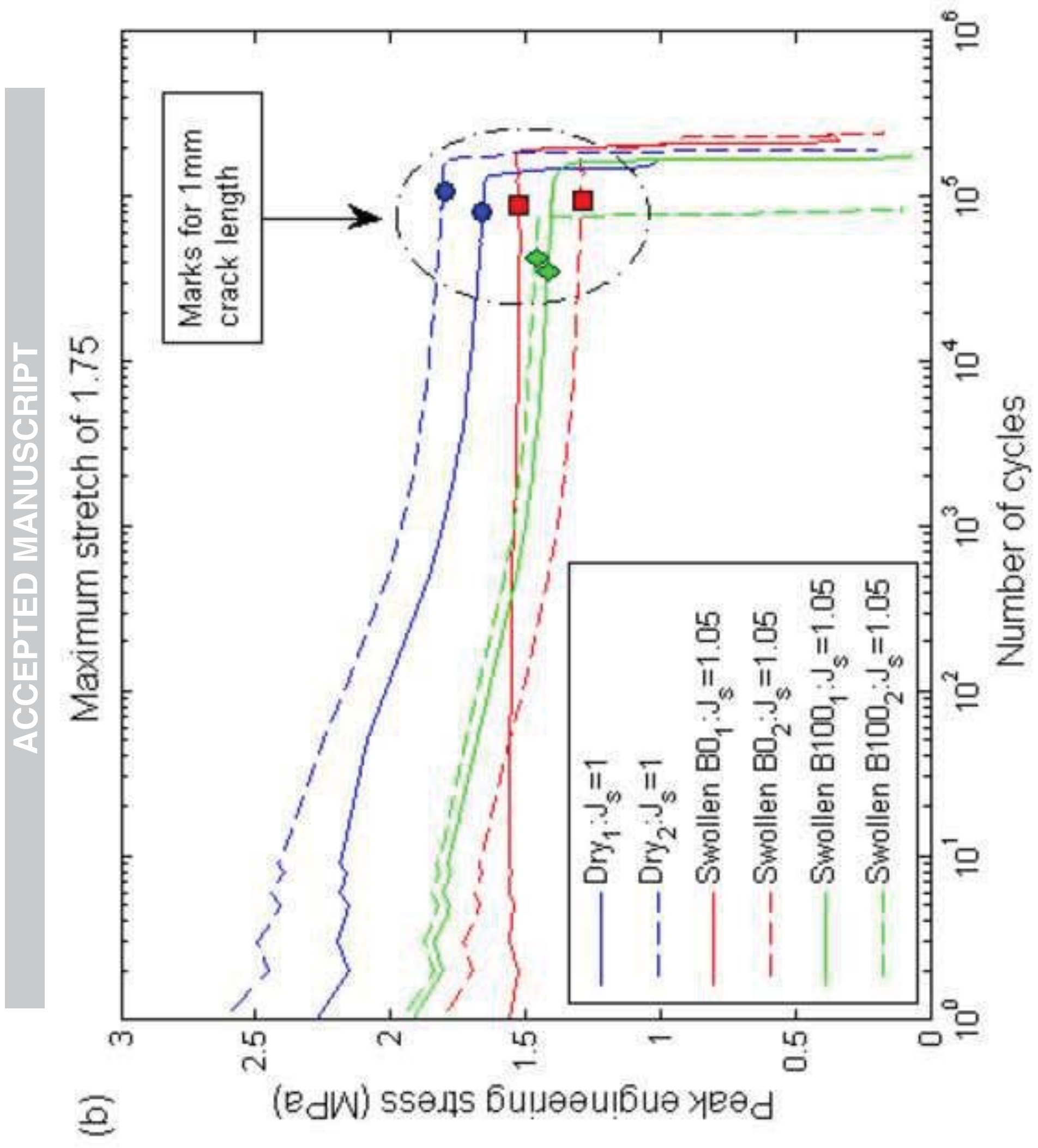




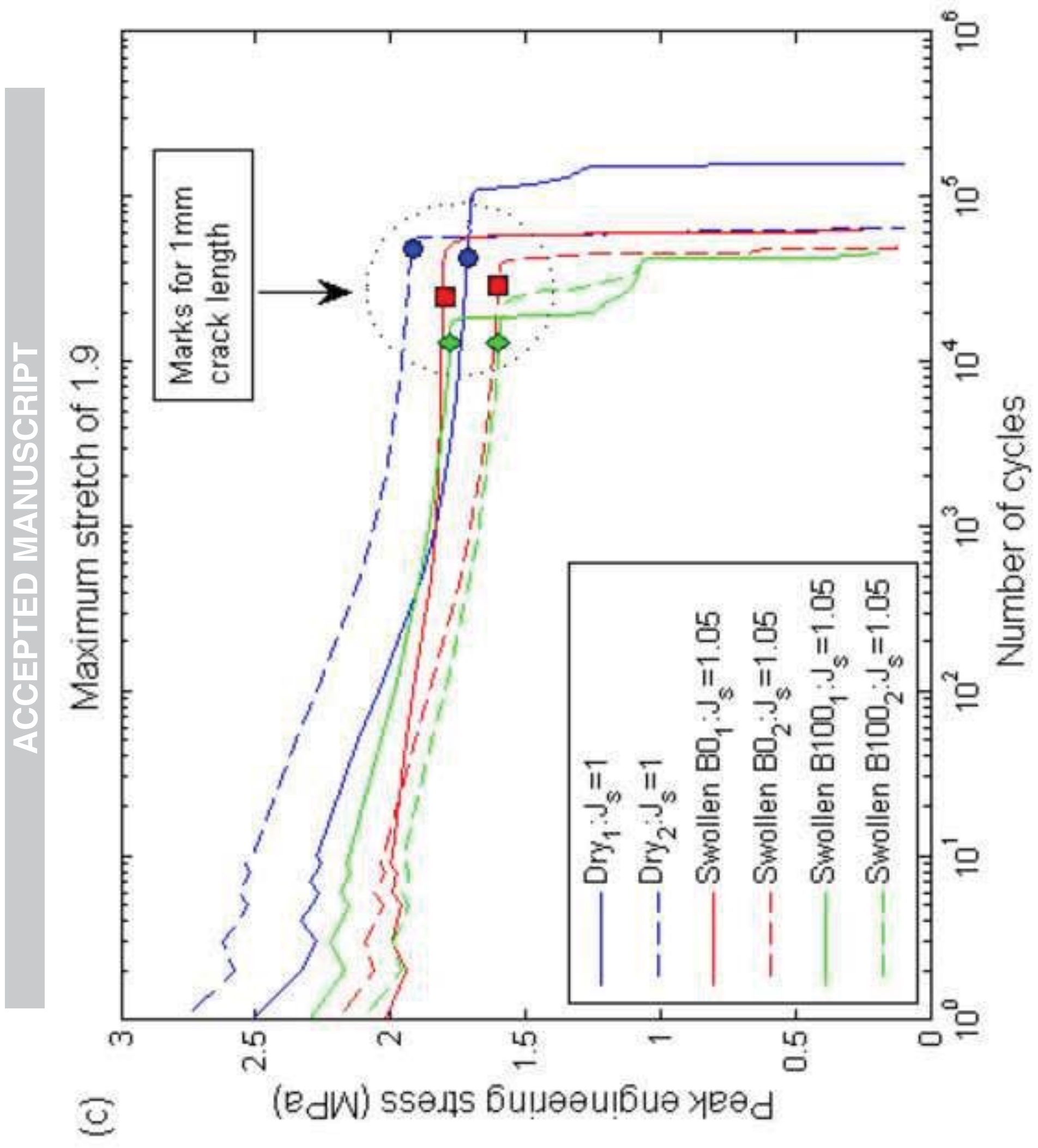




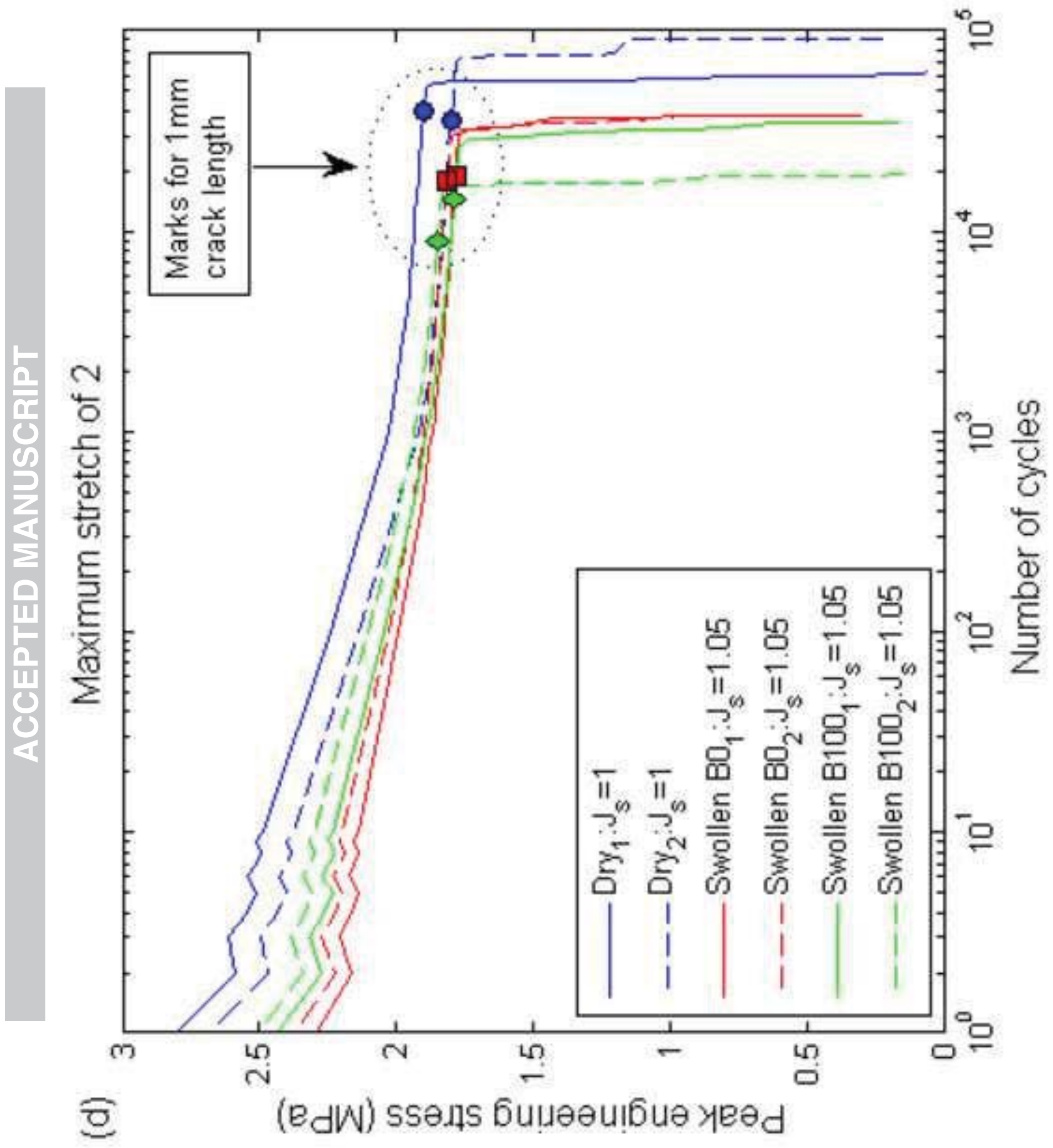




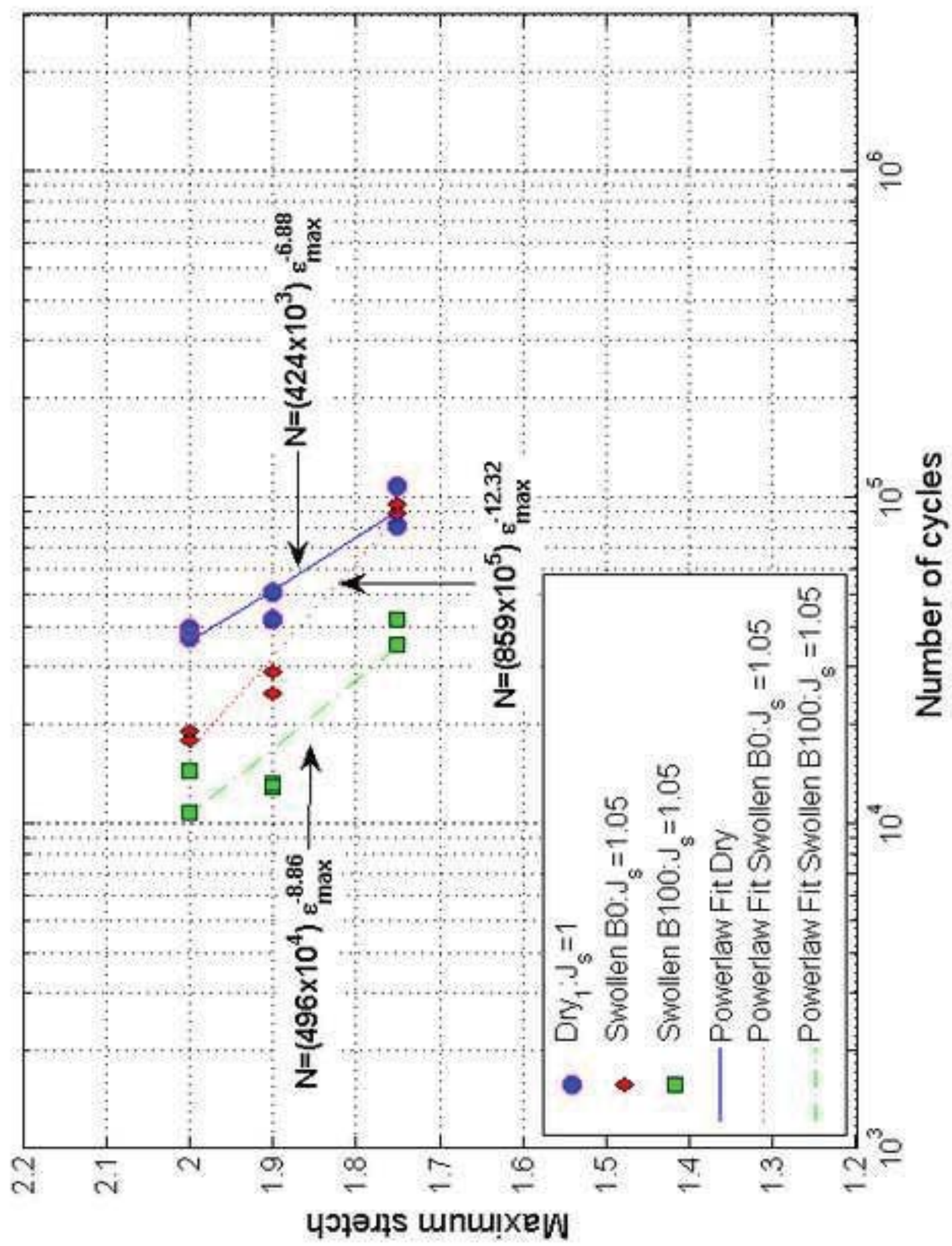




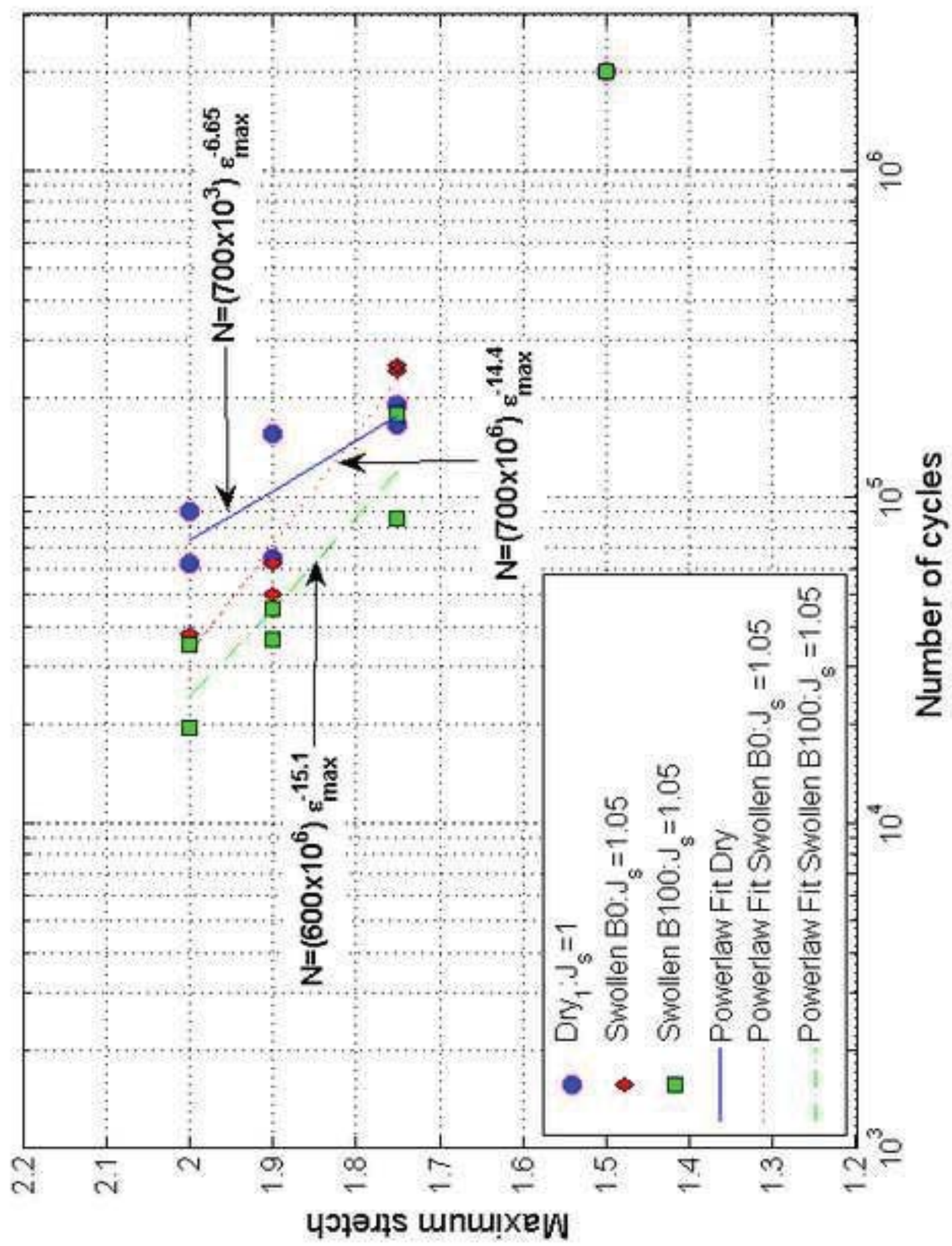




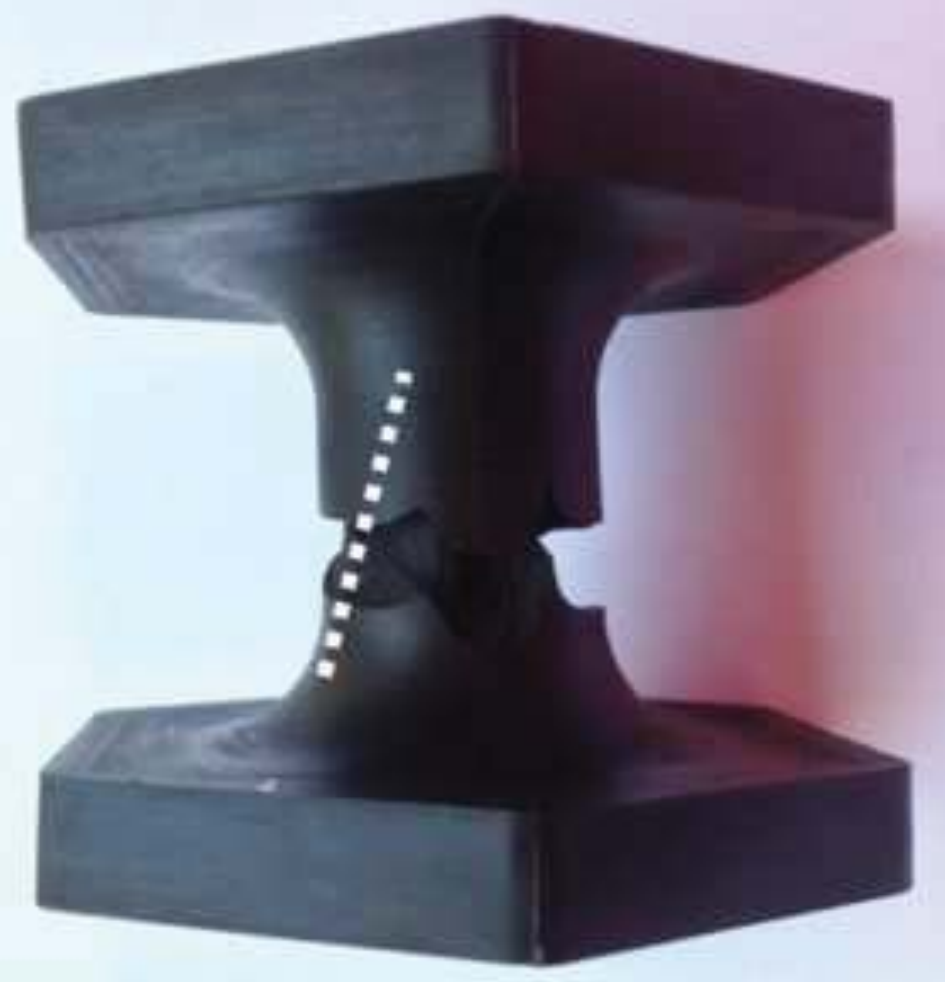




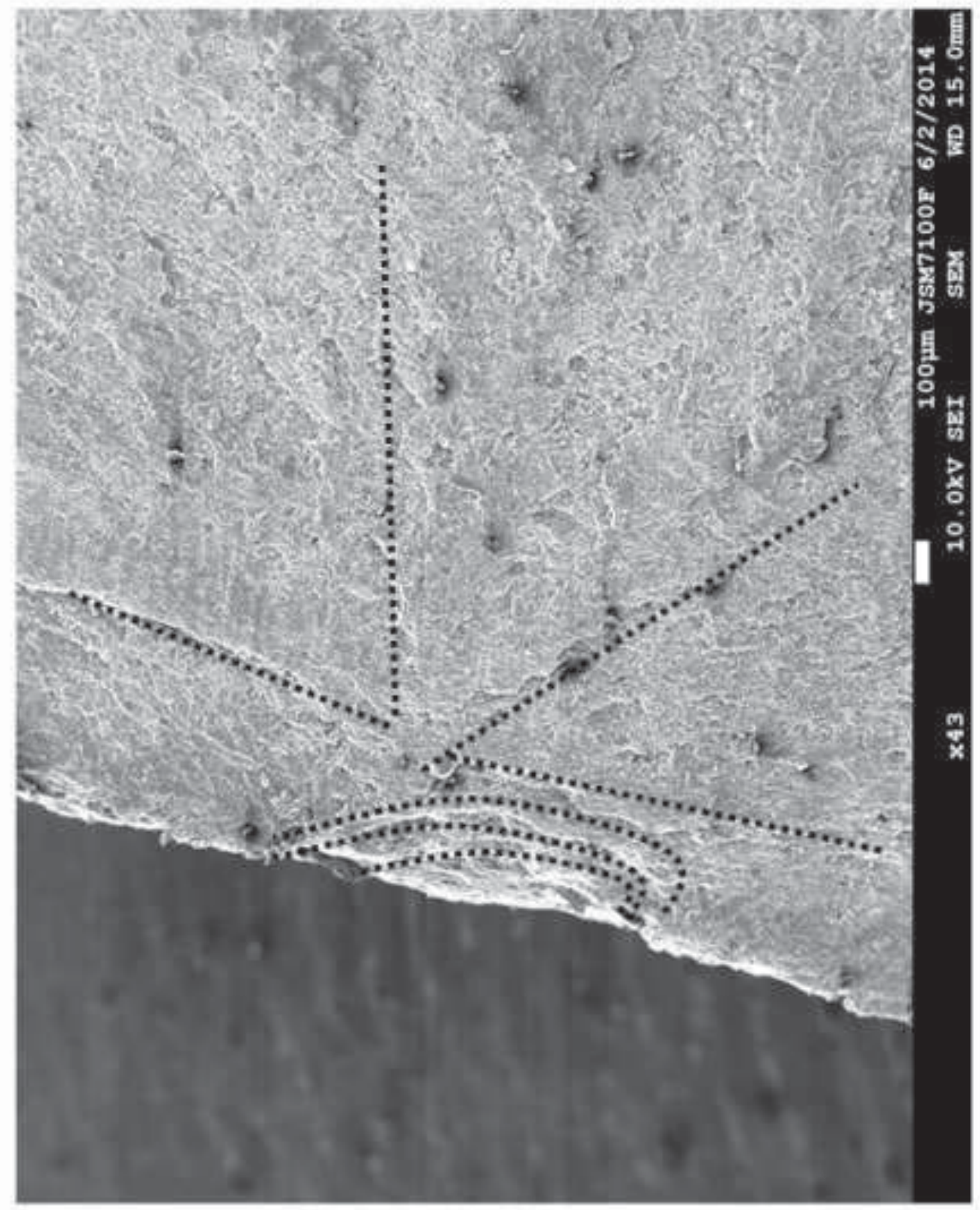




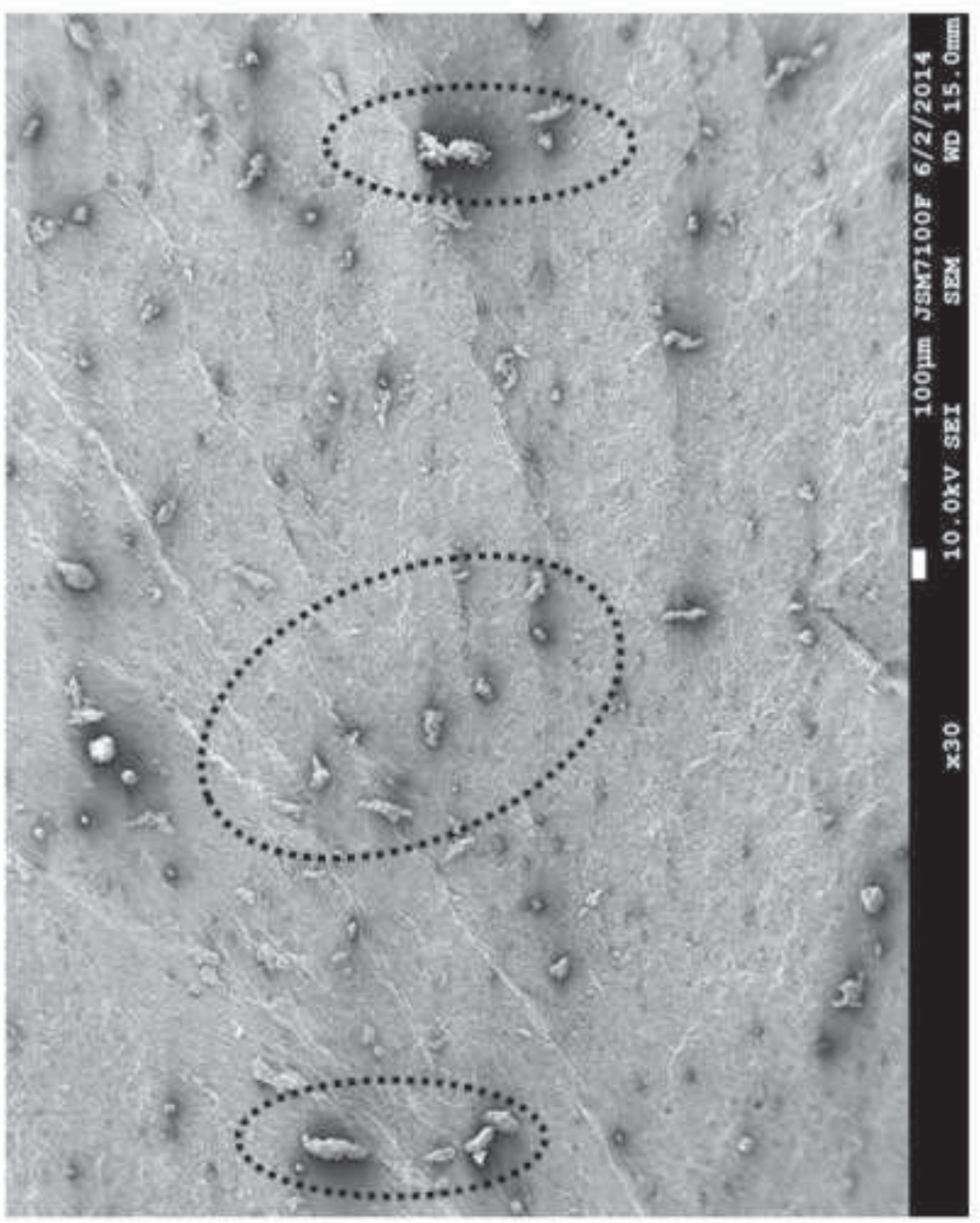

${ }^{\prime} \Delta$ 


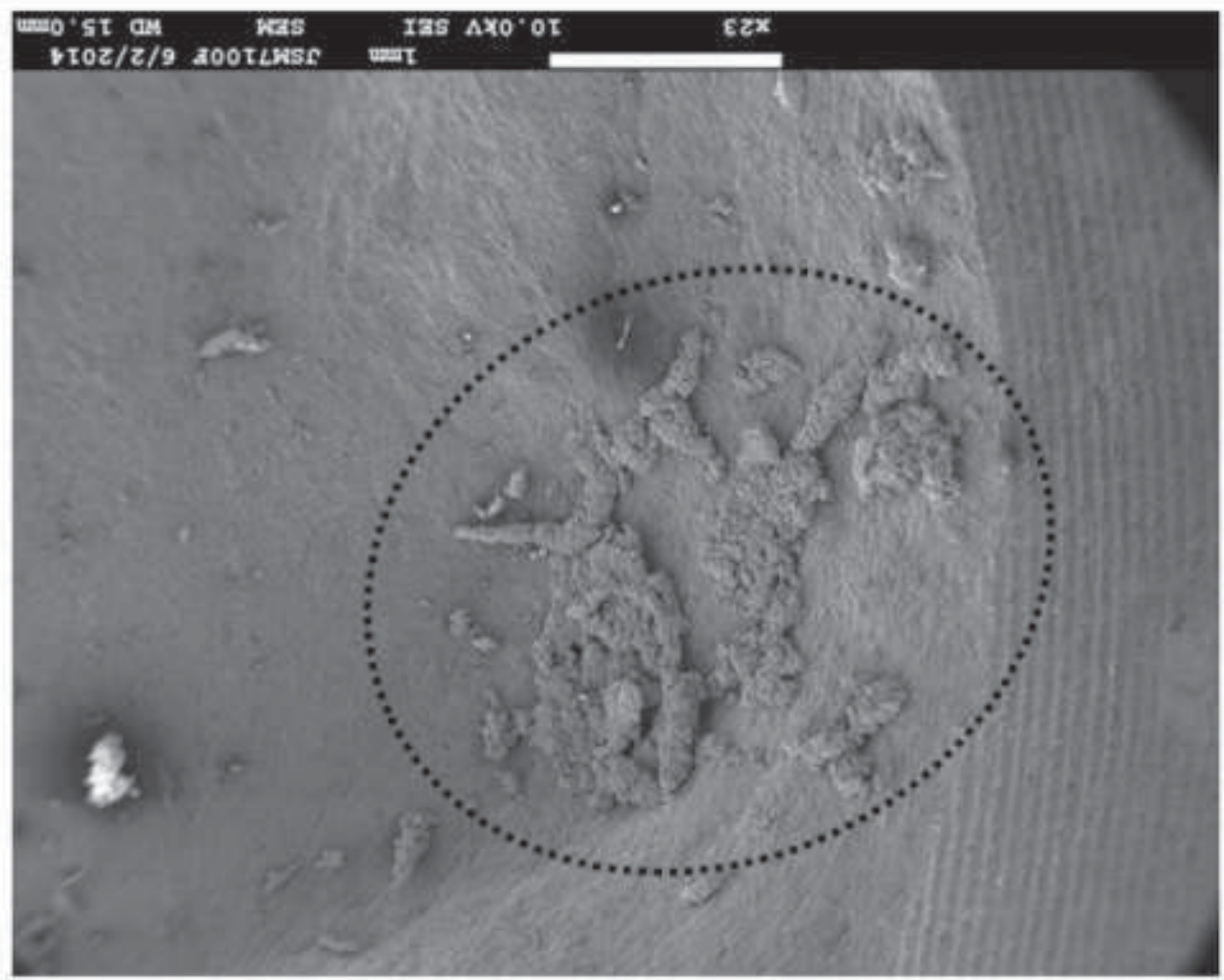

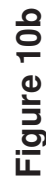




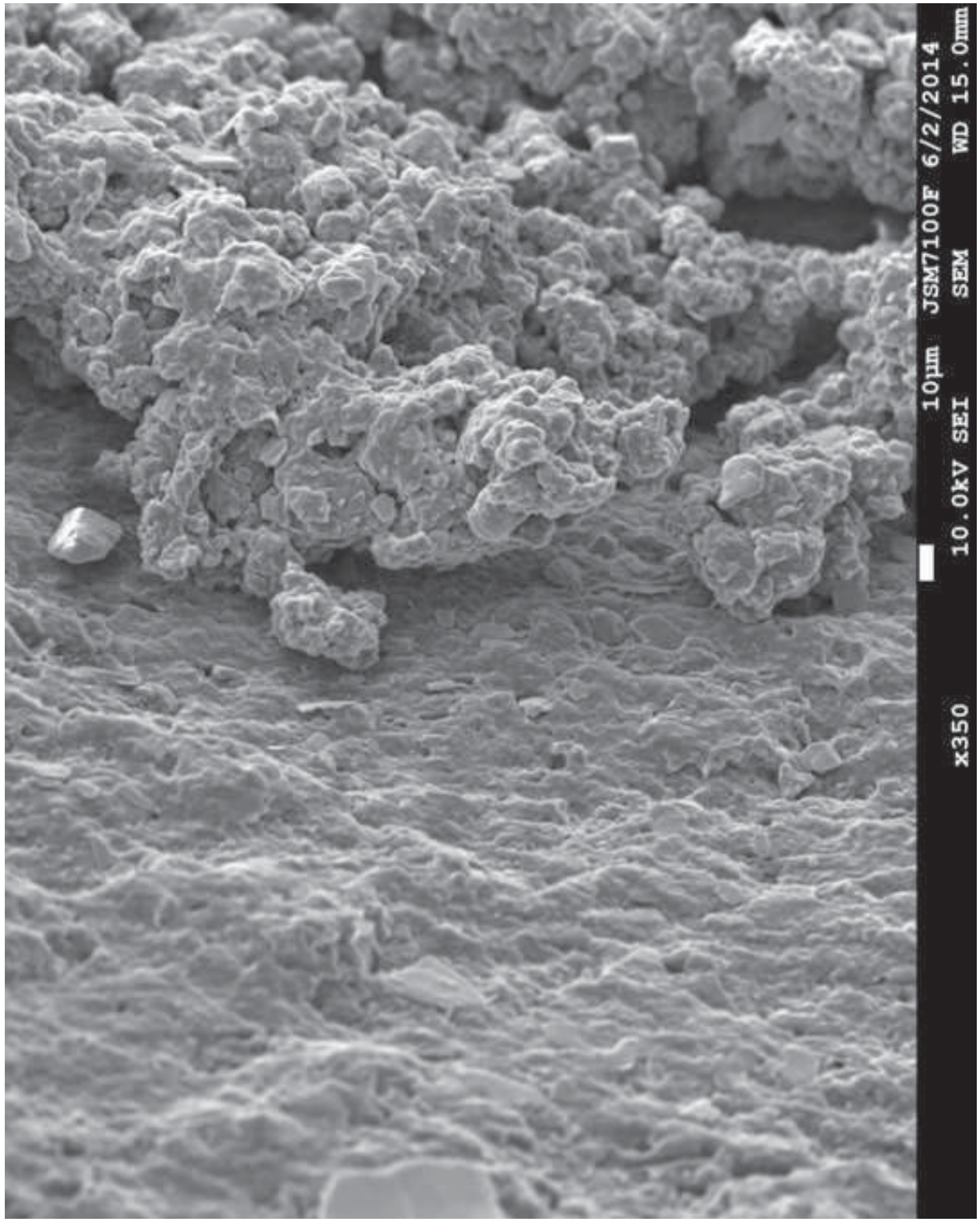




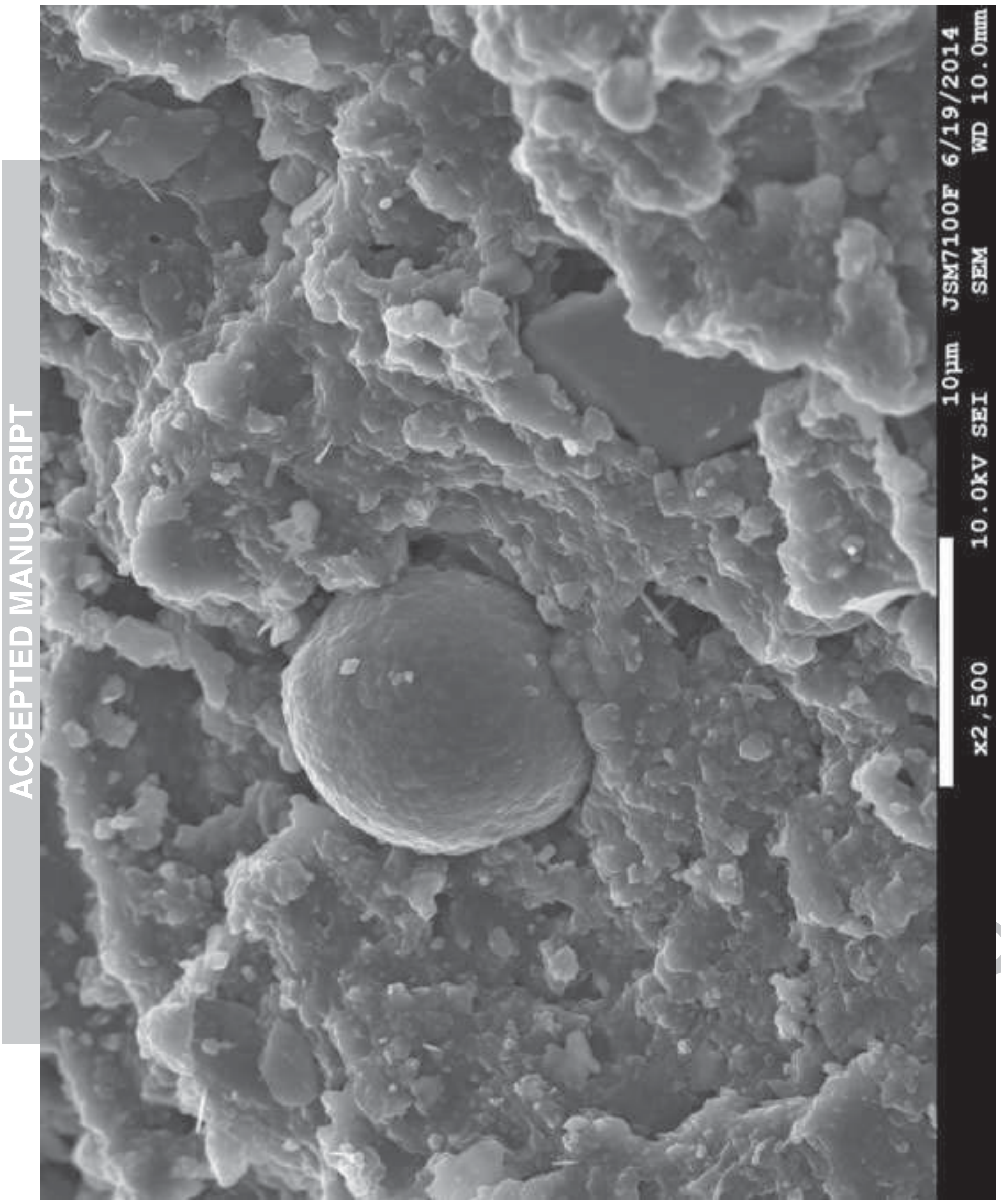




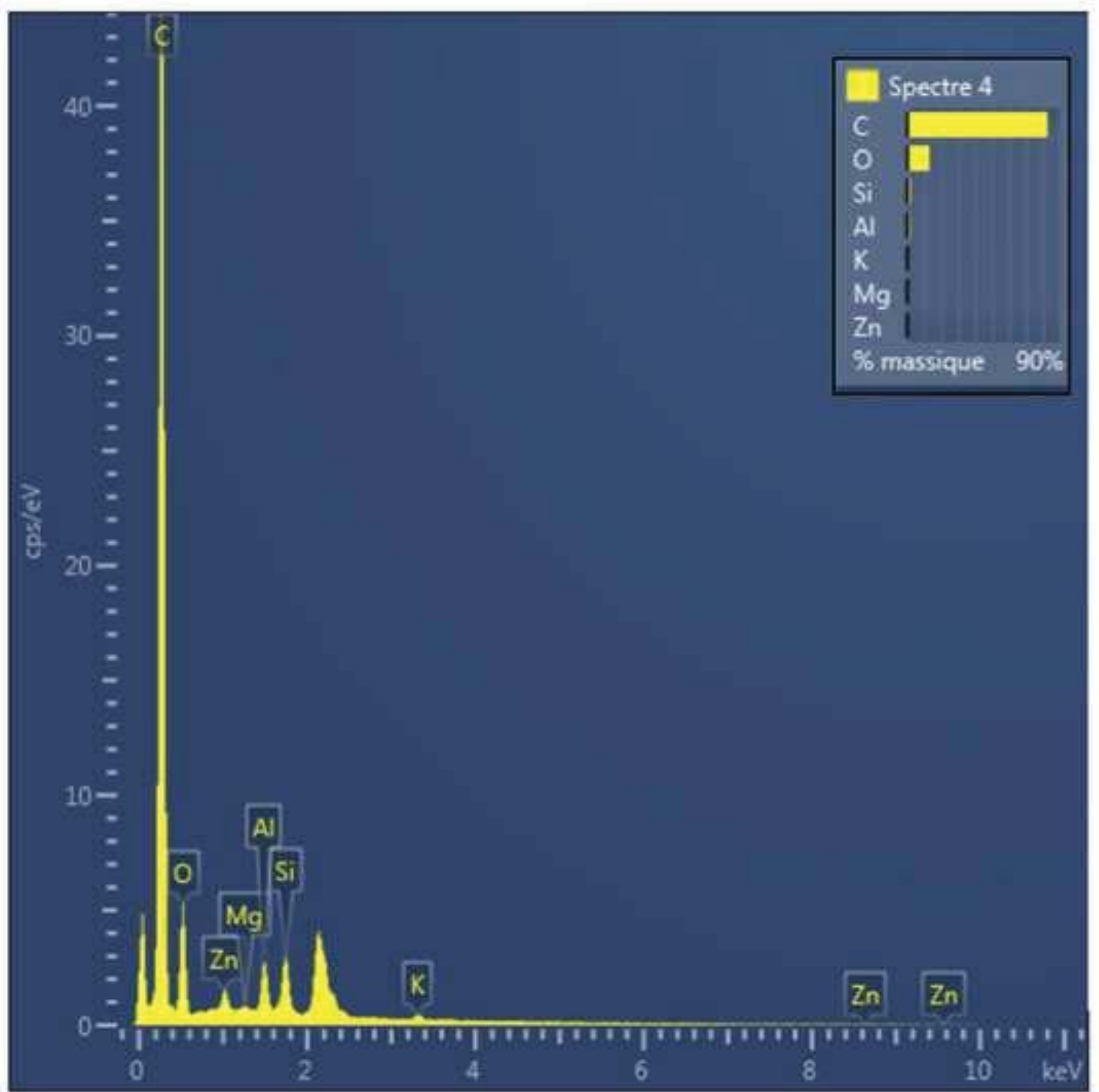




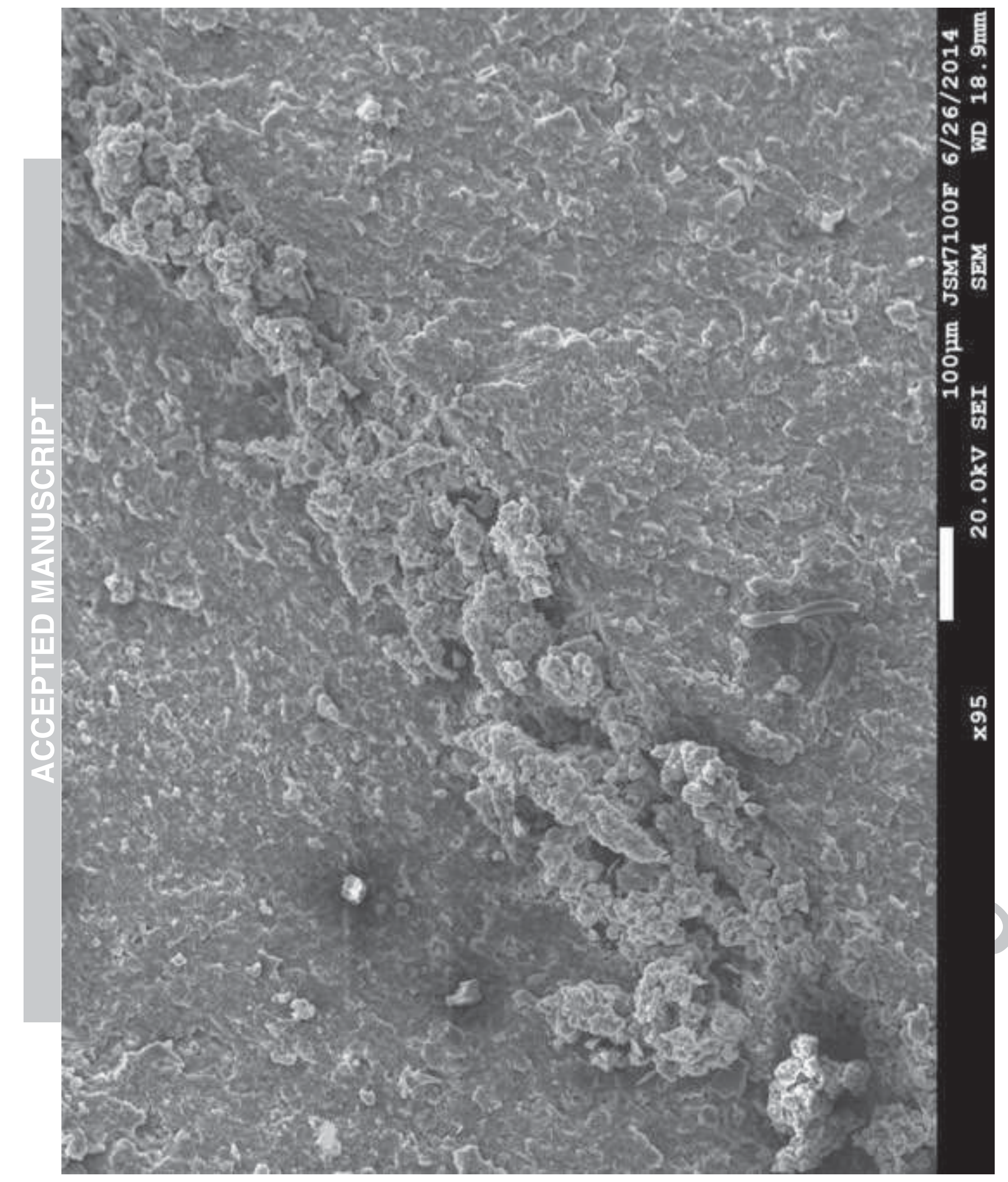




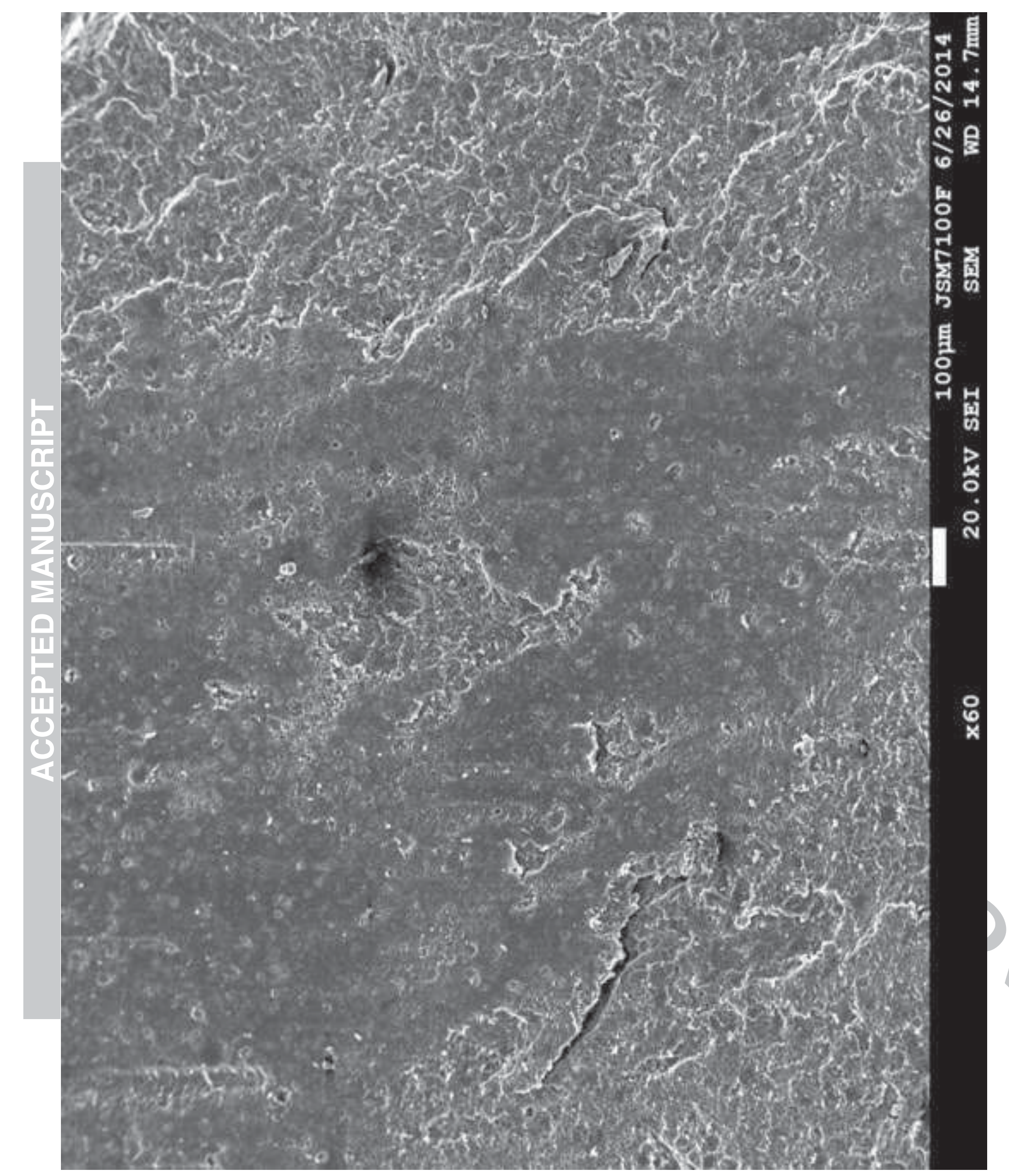




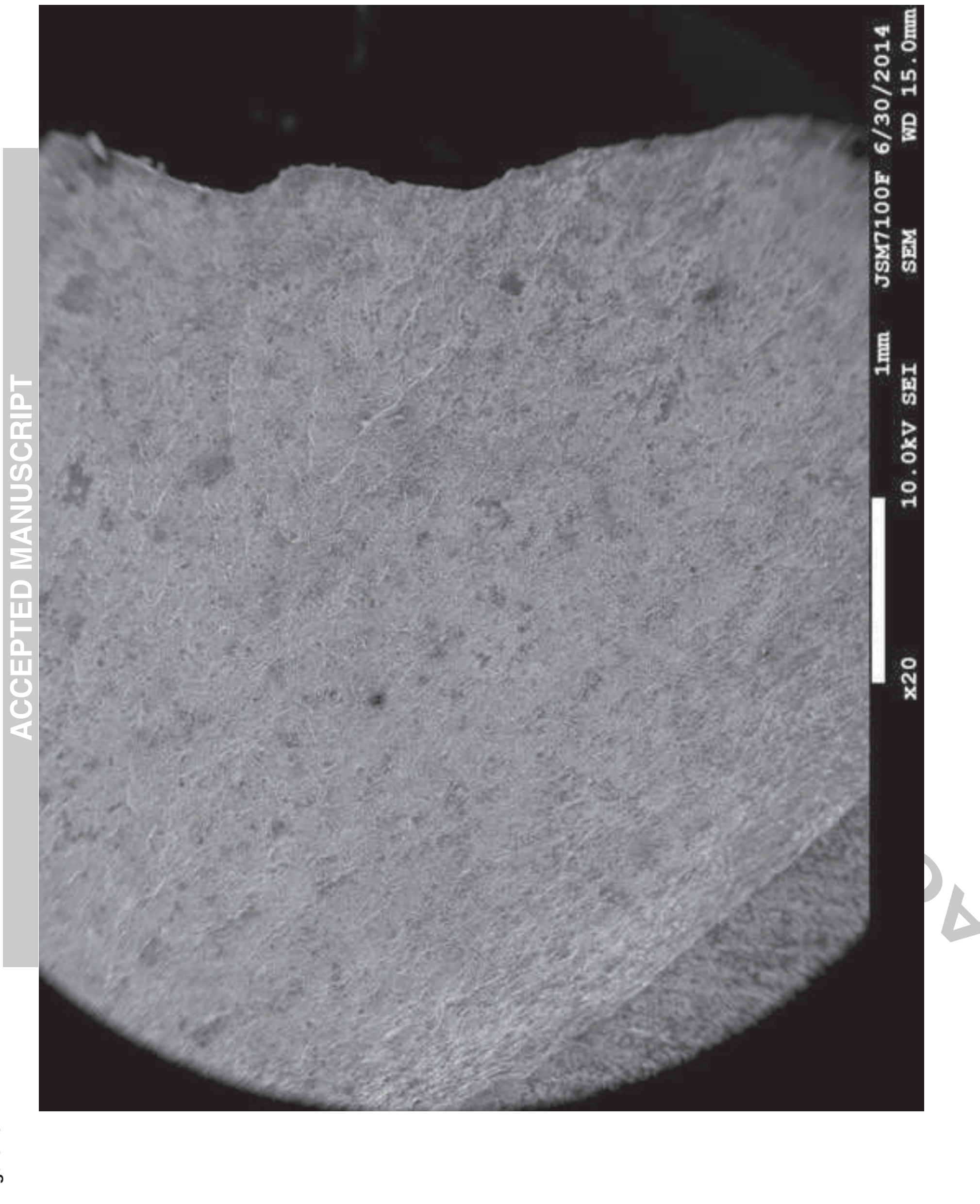


Table 1

\begin{tabular}{|l|c|c|c|}
\hline \hline Test & $\%$ Unit & Methods & Results \\
\hline \hline Ester content & $\%(\mathrm{~m} / \mathrm{m})$ & EN 14103 & 96.9 \\
Density at $15{ }^{\circ} \mathrm{C}$ & $\mathrm{kg} / \mathrm{m}^{3}$ & EN ISO 12185 & 875.9 \\
Viscosity at $40^{\circ} \mathrm{C}$ & $\mathrm{mm}^{2} / \mathrm{s}$ & EN ISO 3104 & 4.667 \\
Flash point & ${ }^{\circ} \mathrm{C}$ & EN ISO 3679 & 168 \\
Cetane number & - & EN ISO 5165 & 69.7 \\
Water content & $\mathrm{mg} / \mathrm{kg}$ & EN ISO 12937 & 155 \\
Acid value & $\mathrm{mgKOH} / \mathrm{g}$ & EN ISO 3679 & 0.38 \\
Methanol content & $\%(\mathrm{~m} / \mathrm{m})$ & EN 14110 & $<0.01$ \\
Monoglyceride content & $\%(\mathrm{~m} / \mathrm{m})$ & EN 14105 & 0.67 \\
Diglyceride content & $\%(\mathrm{~m} / \mathrm{m})$ & EN 14105 & 0.2 \\
Triglyceride content & $\%(\mathrm{~m} / \mathrm{m})$ & EN 14105 & 0.2 \\
Total glycerine & $\%(\mathrm{~m} / \mathrm{m})$ & EN 14105 & 0.25 \\
\hline \hline
\end{tabular}

Table 2

\begin{tabular}{|l|c|c|c|}
\hline \hline Rubber & Volume change (\%) & Immersion Duration & Degree of swelling, $J_{s}$ \\
\hline \hline Dry & 0 & 0 & 1 \\
Swollen B0 & 5 & 3 months & 1.05 \\
Swollen B100 & 5 & 10 days & 1.05 \\
\hline \hline
\end{tabular}


Table 3

\begin{tabular}{|c|c|c|c|}
\hline \hline Rubber & Before testing & After testing & Hardness change (-\%) \\
\hline \hline Dry & 59.5 & 59 & 0.8 \\
Swollen B0 & 54.81 & 49.84 & 9 \\
Swollen B100 & 54.73 & 48.62 & 11 \\
\hline \hline
\end{tabular}

Table 4

\begin{tabular}{|c|c|c|c|}
\hline \hline Rubber & Before testing $(\mathrm{g})$ & After testing $(\mathrm{g})$ & Mass change (-\%) \\
\hline \hline Dry & 127.25 & 127.24 & 0 \\
Swollen B0 & 131.69 & 131.17 & 0.39 \\
Swollen B100 & 131.36 & 130.86 & 0.38 \\
\hline \hline
\end{tabular}

Table 5

\begin{tabular}{|c|c|c|c|c|}
\hline \hline Features & Maximum Stretch & Dry & Swollen B0 & Swollen B100 \\
\hline \hline \multirow{3}{*}{ Smooth and rough surface } & 1.5 & & $\mathrm{X}$ & $\mathrm{X}$ \\
& 1.75 & & & $\mathrm{X}$ \\
& 1.9 & & $\mathrm{X}$ \\
\hline \multirow{3}{*}{ Clouded wool $(\mathrm{CW})$} & 2 & & $\mathrm{X}$ & $\mathrm{X}$ \\
& 1.5 & $\mathrm{X}$ & $\mathrm{X}$ \\
& 1.75 & $\mathrm{X}$ & $\mathrm{X}$ & $\mathrm{X}$ \\
\hline & 1.9 & & $\mathrm{X}$ & $\mathrm{X}$ \\
Crack initiation at surface & 2 & $\mathrm{X}$ & $\mathrm{X}$ & $\mathrm{X}$ \\
& 1.5 & $\mathrm{X}$ & $\mathrm{X}$ & $\mathrm{X}$ \\
\hline & 1.75 & $\mathrm{X}$ & $\mathrm{X}$ & \\
& 2 & & $\mathrm{X}$ & $\mathrm{X}$ \\
\hline
\end{tabular}


- The fatigue behaviour of swollen nitrile rubbers at the same degree of swelling is investigated.

- Fatigue tests are carried out under uniaxial loading conditions.

- The fatigue lifetime is found longest for dry, followed by swollen in B0 and B100.

- Loading conditions are found to have no effect on the crack initiation and propagation zone.

- Fatigue cracks initiate at the surface in dry and swollen rubbers. 